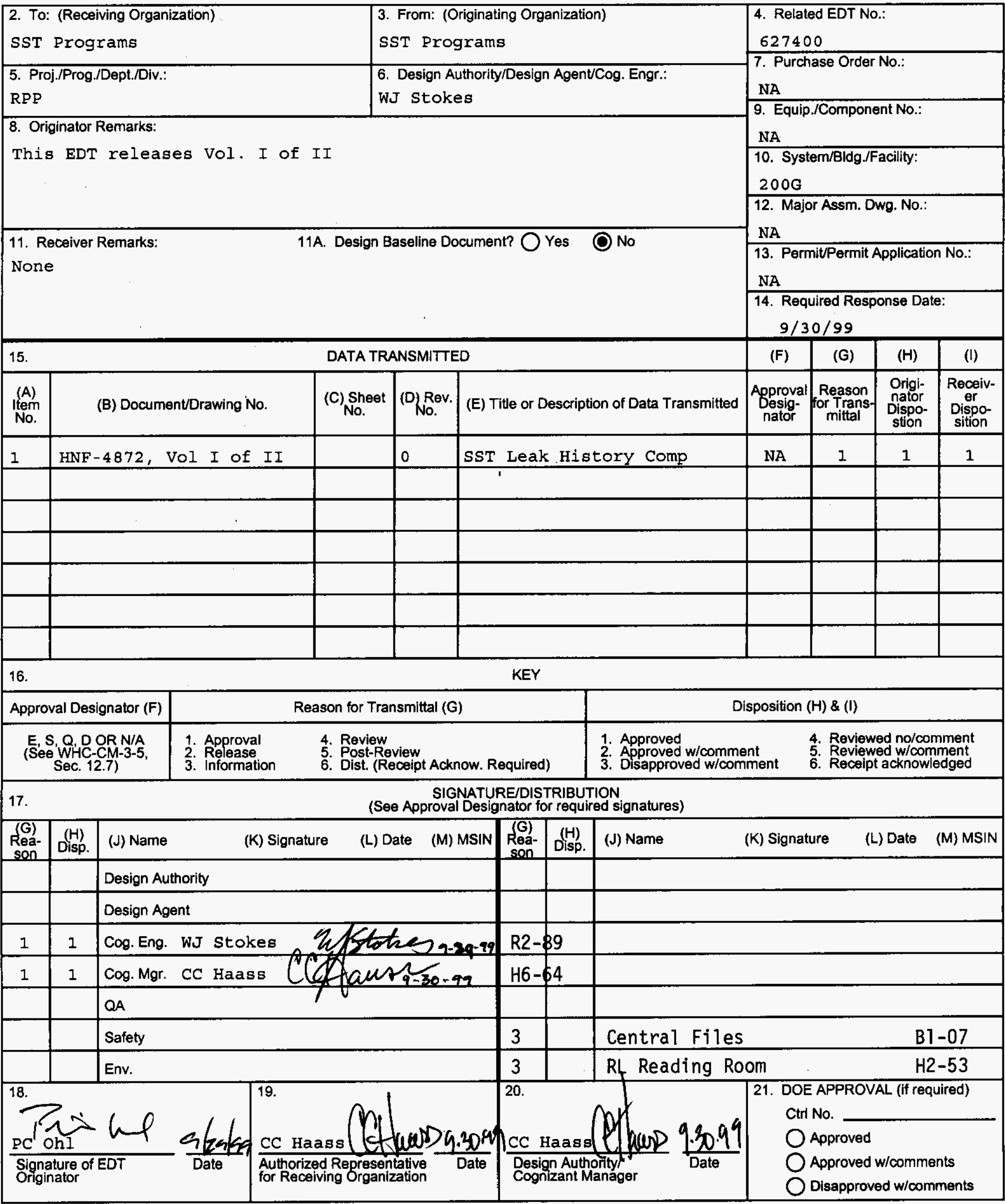




\title{
Single-Shell Tank Leak History Compilation Volume I of II: Summary
}

\author{
JL Nelson and PC Ohl of Vista Research, Ine \\ Lockheed Martin Hanford Corporation \\ Richland, WA 99352 \\ U.S. Department of Energy Contract DE-AC06-96RL13200 \\ $\begin{array}{lll}\text { EDT/ECN: } 627399 & \text { UC: } 2010 \\ \text { Org Code: } 73500 & \text { Charge Code: } 106493 \text { BA20 pa (HN9A0211) } \\ \text { B\&R Code: } & \text { EW3130010 } & \text { Total Pages: } 5859\end{array}$
}

Key Words: SST, Leak, Leaking, Tank

Abstract: This report is a compilation of leak histories associated with the Hanford single-shell tanks. The report reviews leak volume estimates, leak rates, and leak declaration procedures.

TRADEMARK DISCLAIMER. Reference herein to any specific commercial product, process, or service by trade name, trademark, manufacturer, or otherwise, does not necessarily constitute or imply its endorsement, recommendation, or favoring by the United States Government or any agency thereof or its contractors or subcontractors.

Printed in the United States of America. To obtain copies of this document, contact: Document Control Services, P.O. Box 950, Mailstop H6-08, Richland WA 99352, Phone (509) 372-2420; Fax (509) 376-4989.

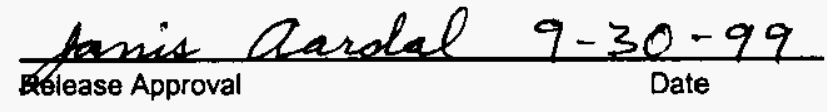

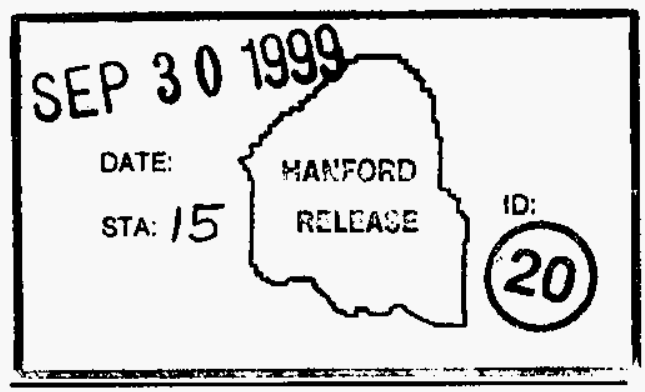

Release Stamp

\section{Approved For Public Release}




\section{Single-Shell Tank Leak History Compilation}

Volume I of II: Summary

LMHC Subcontract No. 00003012

Vista Research Project No. F015

Prepared by:

James L. Nelson

Phillip C. Ohl

Prepared for:

U.S. Department of Energy - Office of River Protection c/o Lockheed Martin Hanford Corporation

P.O. Bcx 1500

Richland, WA 99352-1505

September 1999

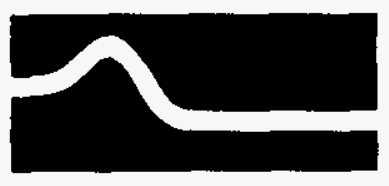


This page intentionally left blank 


\section{Executive Summary}

Single-shell tanks (SSTs) were initially constructed at Hanford in 1944 to store radioactive wastes resulting from plutonium/uranium separations processes necessary for plutonium production. The first SST suspected of leaking was tank U-104 in 1956 followed by tanks TY-106 and U-101 in 1959. Seven tanks have been identified as catastrophic leakers, with estimated leak volumes of greater than 50,000 gallons or estimated leak rates greater than 10 gallons per hour (A-105, BX-102, SX-110, SX-113, SX-115, T-106 and U-104). To date, 67 of the total 149 single-shell tanks have been declared to be "confirmed or assumed leakers". While most of the SSTs have had the supernatant pumped off (or interim-stabilized) many of the tanks contain significant volumes of supernatant, interstitial liquids, or both. These tanks represent a potential insult to the environment should a failure occur prior to or during their retrieval. Under the current SST Retrieval Program Plan, the contents of the SSTs are scheduled for "retrieval" with various hydraulic (sluicing-based) technologies. A primary input to this plan is the characterization of the current condition of the SSTs.

This report provides a summary of the reference material available for SST leak information. A discussion of tank leak histories at Hanford and the Savannah River Site is provided, as well as an assessment of tank leak mechanisms, leak rates, and leak detection procedures. Volume II of this report tabulates over 500 bibliographic references for Hanford tank integrity data and provides a single data package release of selected relevant report sections associated with historical SST leaks.

Today, all SSTs are monitored through the tank surveillance and monitoring program according to approved monitoring frequencies with approved leak detection methods. There are no known actively leaking SSTs at this time. 
This page intentionally left blank 


\section{Table of Contents}

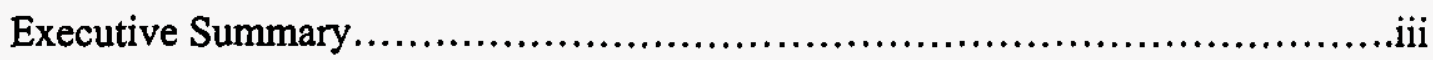

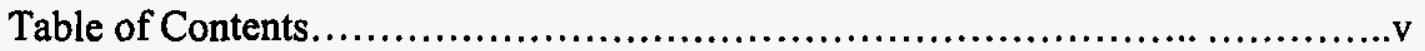

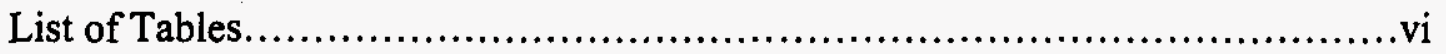

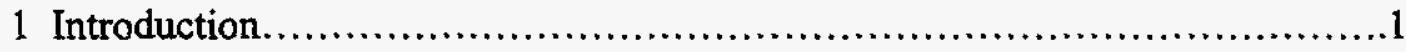

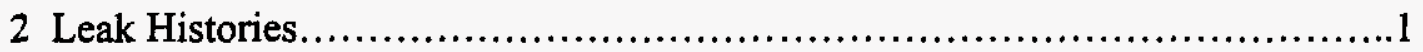

2.1 Hanford Leak Histories...............................................

2.2 Savannah River Leak Histories....................................

3 Leak Declaration Criteria/Procedures at Hanford................................... 6

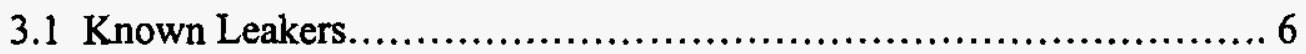

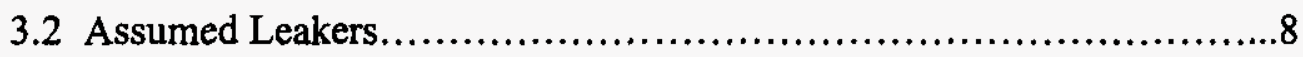

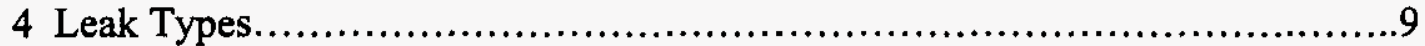

4.1 Catastrophic Leaks (Greater than 50,000 gal) ........................15

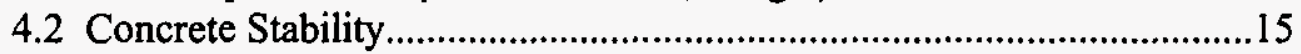

5 Leak Data Basis Review........................................................16

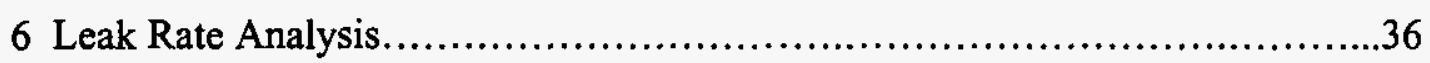

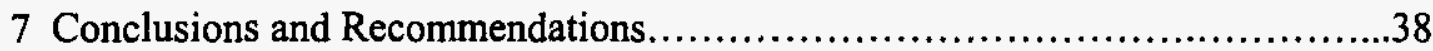

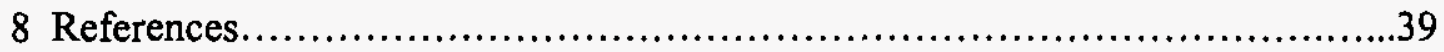

Appendix A - Tank Specific Data Tables

Volume II - Data Package 


\section{Tables}

Table 1. Single-Shell Tank Leak Volume Estimates 3

Table 2. Savannah River Site Tank Characteristics 4

Table 3. Leak Volumes Based on Liquid Level Decreases 7

Table 4. Leak Volumes Based on Factors Other than Liquid Level 8 Decreases

Table 5. Suspect Leakers for which Liquid Level Decreases Could not 9 be Confirmed

Table 6. Corrosivity Factors from Primary Waste Types 10

Table 7. Waste Grouping vs. Leak Status and Corrosivity Factor 11

Table 8. SSTs with Bulged Bottoms 13

Table 9. Strontium and Cesium Recovery Sluicing Campaign 14

Table 10. Uranium Recovery Sluicing Campaigns 14

Table 11. Catastrophic Leaks in SSTs 15

Table 12. Leak Rates for some Hanford and Savannah River SSTs 37 
This page intentionally left blank 


\section{$1 \quad$ Introduction}

Under the SST Retrieval Program Plan, the contents of the Hanford single-shell tanks (SSTs) are scheduled for "retrieval" with various hydraulic (sluicing-based) technologies. A primary input to this plan is the characterization of the current condition of the SSTs.

Since the SSTs were taken out of service, a number of circumstances regarding SST waste retrieval have changed. First, some of the SSTs have been "interim stabilized"; that is, pumpable liquids have been removed, leaving sludge and salt cake in a stable condition while they await retrieval). Second, there has been some degradation of tank liners. Third, the "leak designation" of some SSTs has changed (i.e., whether they are considered leaking or not). And fourth, there have been changes in retrieval technology. All of these circumstances must be considered in context in order to devise a viable retrieval strategyone that allows efficient waste retrieval and at the same time minimizes the risk of leaks into the vadose zone. As the condition of the tanks continues to degrade, retrieval options may become limited to technologies that would not cause further degradation (at least not to the point of creating new leaks). An evaluation of the leak bistory of SSTs is an important part of the determination of the appropriate retrieval technique for the wastes.

Today, all SSTs are monitored through the tank surveillance and monitoring program according to established and approved monitoring frequencies with established and approved methods. There are no known actively leaking SSTs at this time.

\section{$2 \quad$ Leak Histories}

\subsection{Hanford Leak Histories}

Single-shell tanks were initially constructed at Hanford in 1944 to store radioactive wastes resulting from plutonium/uranium separation processes necessary for plutonium production. The first SSTs to leak were TY-106 and U-101, in 1959. To date, 67 out of a total of 149 SSTs have been declared "known" or "assumed leakers." The approach used to determine what constitutes a "leaker" has not been consistent. Anecdotal information indicates that, in some circumstances, a leak was merely inferred-on the basis of partial or inconclusive data. Accordingly, not all "assumed leakers" may actually have leaked. The SSTs were formally removed from active service in 1981, but they still contain over 35 million gallons of radioactive waste that has not yet been retrieved. Table 1 provides a summary of leak dates and leak volume estimates [Hanlon, 1999].

During the 37 years that the SSTs were in active service, 13 different types of waste were generated [Hill, 1994]-the result of various processes for plutonium/uranium separation, uranium recovery, and cesium/strontium removal. These 13 distinct wastes have been mixed together as a result of consolidation efforts and the cascading of wastes to form 30 discrete tank groupings by specific waste chemistry [Anantatmula, 1994]. 
Since 1978, 119 SSTs have been "interim-stabilized." Interim stabilization is the process of removing pumpable liquids from the tanks, leaving the sludge and salt cake in a stable condition while they await retrieval. Even after the supernatant liquids have been pumped off, SSTs may contain significant volumes of interstitial liquids--liquids contained in the void space between the grains and particles that comprise the sludge and the wetted portions of the salt cake. Section 5 presents a discussion of individual tank leak histories. 
Table 1. Single Shell Tank Leak Volume Estimates (Reprinted from Hanlon, 1999)

\begin{tabular}{|c|c|c|c|}
\hline $\begin{array}{c}\text { Tank } \\
\text { Number }\end{array}$ & $\begin{array}{l}\text { Date Declared, } \\
\text { Confirmed, or } \\
\text { Assumed Leaker }\end{array}$ & Leak Volume (gallons) & $\begin{array}{c}\text { Leak Estimate } \\
\text { Updated }\end{array}$ \\
\hline 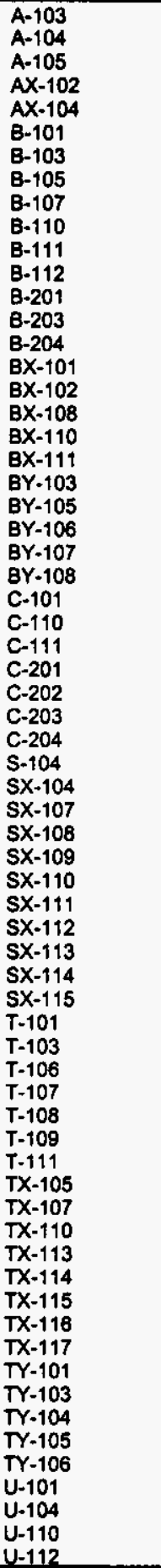 & 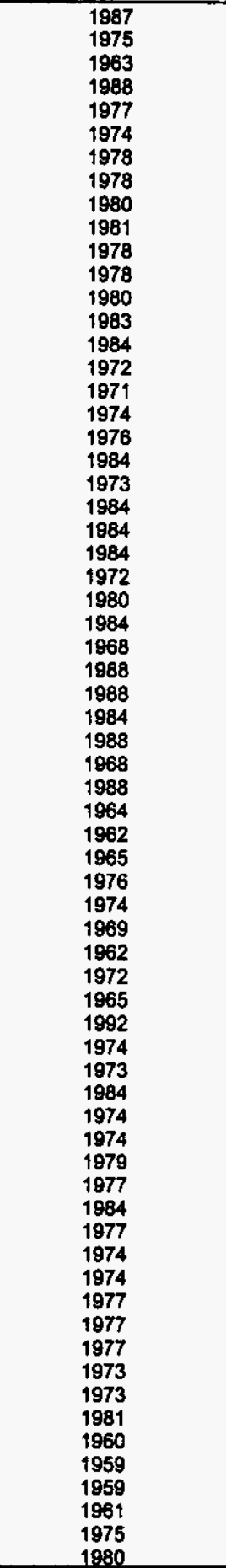 & 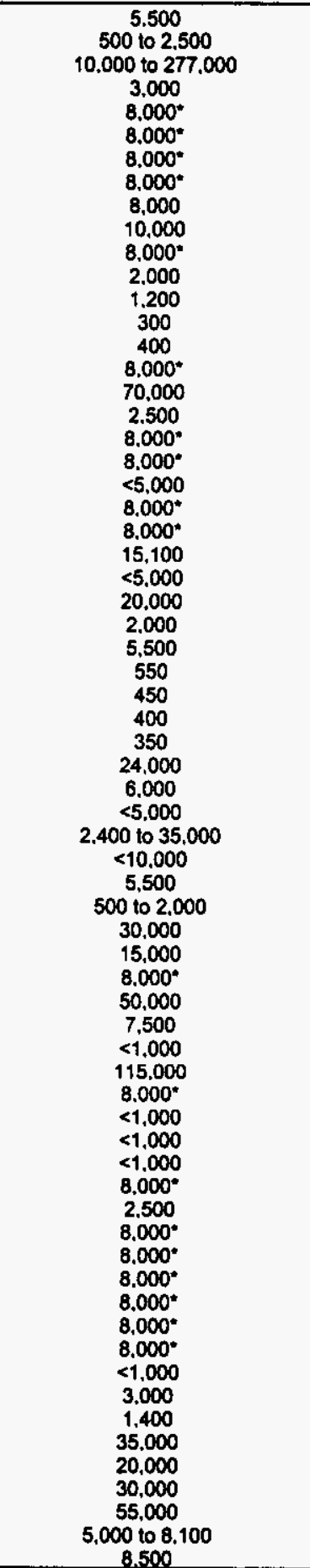 & 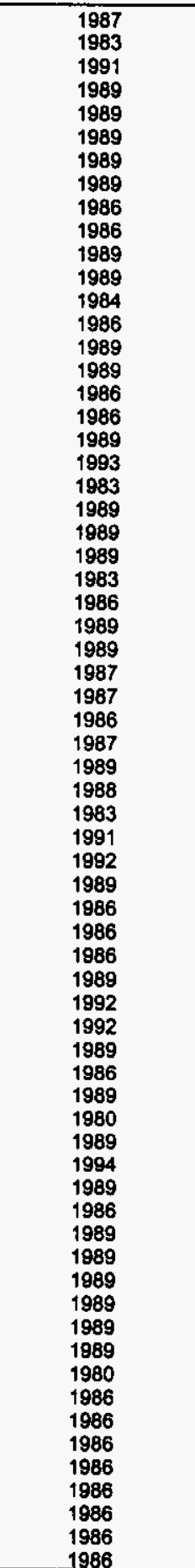 \\
\hline
\end{tabular}

- Average leak volume for 19 tanks with a total estimated leak volume of 150,000 gallons 


\subsection{Savannah River Site Leak Histories}

Due to the similarity between Savannah River Site and Hanford tanks, wastes, and leak events a brief review of Savannah River Site leak histories is included in this report. Much of the knowledge base surrounding radioactive tank leaks was developed from laboratory and field inspection data at the Savannah River Site.

Eleven of the primary liners of the first generation tanks at the Savannah River Site have developed cracks. These were the non-stress-relieved design of high heat waste tanks of Type I (1F and 9H through $12 \mathrm{H})$ and Type II $(13 \mathrm{H}$ through $16 \mathrm{H})$ design and low heat Type IV (17F through $20 \mathrm{~F}$ and $21 \mathrm{H}$ through $24 \mathrm{H})$ design. One of these tanks $(16 \mathrm{H})$ had waste overflow the secondary steel pan confinement and leak into the soil. This tank was drained and retired from service. Table 2 provides a summary of tank characteristics at the Savannah River Site.

Table 2. Savannah River Site Tank Characteristics

\begin{tabular}{|c|c|c|c|c|c|c|c|}
\hline Tank No. & Type & $\begin{array}{l}\text { Year } \\
\text { Built }\end{array}$ & Material & $\begin{array}{l}\text { Capacity } \\
\text { (Kgal) }\end{array}$ & Confinement & $\begin{array}{l}\text { Dimensions } \\
\text { (D X H, ft) }\end{array}$ & $\begin{array}{l}\text { Stress } \\
\text { Relief }\end{array}$ \\
\hline $1 F-8 F$ & I & 1952 & A285 & 750 & Annulus Pan & $75 \times 24.5$ & No \\
\hline $9 \mathrm{H}-12 \mathrm{H}$ & I & 1953 & A285 & 750 & Annulus Pan & $75 \times 24.5$ & No \\
\hline $13 \mathrm{H}-16 \mathrm{H}$ & II & 1956 & A285 & 1,030 & Annulus Pan & $85 \times 27$ & No \\
\hline $17 \mathrm{~F}-20 \mathrm{~F}$ & IV & 1958 & $\mathrm{~A} 285$ & 1,300 & Single wall & $85 \times 34$ & No \\
\hline $21 \mathrm{H}-24 \mathrm{H}$ & IV & 1962 & A285 & 1,300 & Single wall & $85 \times 34$ & No \\
\hline $\begin{array}{l}25 \mathrm{H}-32 \mathrm{H} \\
33 \mathrm{~F}-34 \mathrm{~F} \\
35 \mathrm{H}-37 \mathrm{H} \\
38 \mathrm{H}-43 \mathrm{H} \\
44 \mathrm{~F}-47 \mathrm{~F} \\
48 \mathrm{H}-51 \mathrm{H}\end{array}$ & III & $\begin{array}{l}1967 \\
\text { to } \\
1981\end{array}$ & $\begin{array}{l}\text { A516-70 } \\
\text { A537 }\end{array}$ & 1,300 & Full height liner & $85 \times 33$ & Yes \\
\hline
\end{tabular}

\section{$\underline{\text { SRS Type I Tanks }}$}

Leak detection capability in Type I tanks consists primarily of leak detection probes in the annulus and waste inventory monitoring. Approximately $25 \%$ of the tank walls can be viewed through the annulus with current inspection equipment. Tanks $9 \mathrm{H}$ and $10 \mathrm{H}$ have leaked the most waste. Both tanks began leaking within the first four years of service. Three small leaks have been observed in the upper knuckle plate of Tank $9 \mathrm{H}$, but these leak sites are so small that it is unlikely that they are the only source of the observed annulus deposits. The annulus pan of Tank $9 \mathrm{H}$ contains 8 to 10 in of dried waste. Annulus pans are five feet high and five feet larger in diameter than the $75 \mathrm{ft}$ diameter of these tanks. No leak sites have been observed on the wall of Tank $10 \mathrm{H}$. Two leak sites have been observed in each of Tanks $11 \mathrm{H}$ and $12 \mathrm{H}$. These leaks are covered with dried salts, preventing any estimate of crack length, however they are clearly associated with weldments. The observable leaks in Tank $11 \mathrm{H}$ are 16 to $20 \mathrm{ft}$ above the tank bottom, while the leaks in Tank $12 \mathrm{H}$ are 8 to 9 feet above the tank bottom. Tank $1 \mathrm{~F}$ has also leaked into the annulus, but no leak site can be observed on the tank wall. Tank $11 \mathrm{H}, 12 \mathrm{H}$ and $1 \mathrm{~F}$ were observed to leak after "several years" of operation. All Type I tanks had ultrasonic thickness measurements taken after 12 years and 30 years of operation. No wall thinning has been measurable in any tank [Sindelar, 1995]. 


\section{$\underline{\text { SRS Type II Tanks }}$}

All four Type II tanks have leaked into the annulus. Tank $16 \mathrm{H}$ is estimated to have leaked a maximum of $700 \mathrm{gal}$ of waste above the $5 \mathrm{ft}$ high annulus catch pan, with only a few tens of gallons escaping to the soil. The leakage occurred after 7 months of operation. Subsequent studies determined the cause of failure was nitrate induced stress corrosion cracking. Approximately 175 leak sites have been observed, with approximately 350 estimated, primarily in the heat affected zones of the weld seams between plates. Of ten cracks that have been measured with dye penetrant, the crack lengths in four of these range from 4 to 6 in.

Tank $14 \mathrm{H}$ leaked to the annulus within two years of first operation. Approximately 13 in of dried waste are contained in the catch pan. Inspections have identified 33 leak sites, with an estimated total number of leak sites of about 50 . All but one of the observed leak sites are at the bottom circumferential weld, 30 in above the bottom of the tank. These leaks are assumed to be due to nitrate assisted stress corrosion cracking.

Tank $15 \mathrm{H}$ is believed to have first leaked in 1969,9 years after first service, when the annulus conductivity alarm grounded out. The first two leak sites were observed in 1972 near the bottom circumferential weld. In 1973, eleven additional leak sites were observed in previously uninspected regions. All leaks are believed to be due to nitrate assisted stress corrosion cracking.

Leak sites were observed in tank $13 \mathrm{H}$ in 1977, 21 years after first service. This tank received fresh low heat waste exclusively, while the other three Type II tanks which received fresh high heat waste. The first leak site was 280 in above the tank bottom. The second leak site was observed in 1980 , at the 270 in level.

No significant corrosion has been observed on the outer wall of these tanks. Ultrasonic thickness measurements on tanks $13 \mathrm{H}, 14 \mathrm{H}$, and $15 \mathrm{H}$ indicated no detectable wall thinning between the 12 year and 26 year inspections [Sindelar, 1995].

\section{$\underline{\text { SRS Type III Tanks }}$}

The Type III tanks are the most recently constructed double shell tanks. Twenty-seven Type III tanks were constructed between 1967 and 1981. No cracks or leakage of waste into the annulus have been observed in a Type III tank. Ultrasonic thickness measurements on some of the tanks show no indications of detectable wall thinning. These tanks were stress relief annealed at the time of construction [Sindelar, 1995].

\section{$\underline{\text { SRS Type IV Tanks }}$}

Type IV tanks are single walled, uncooled tanks constructed in 1958 (tanks 17F-20F) and 1962 (tanks $21 \mathrm{H}-24 \mathrm{H}$ ). A leak site was observed in tank $20 \mathrm{~F}$ in 1983 . Three wet spots were observed near tack welds at heights between 22 and $26.5 \mathrm{ft}$ above the tank bottom. These sites were well above the liquid level of waste stored in the tank. One additional leak site was discovered in 1990 at about $26 \mathrm{ft}$ above the tank bottom. The mechanisms 
forming these leak sites has not been determined. Ultrasonic thickness measurements made at 12 years and 24 years of service indicated no detectable wall thinning [Sindelar, 1995].

\section{Leak Declaration Criteria/Procedures at Hanford}

The current procedure for declaration of a tank leak at Hanford is governed by the Tank Waste Remediation System Process Engineering Instruction Manual "Tank Leak Assessment Process," HNF-SD-WM-PROC-021, Section 26.1, Rev 2B (1999). This procedure stipulates initial actions after a first data anomaly is observed, followed by the convening of a review panel and the application of probability assessment decision analysis for the determination of tank integrity. The recommendation resulting from this assessment will result in the tank being classified as "assumed leaker" or "assumed sound." Many existing documents define the two leak classes as "assumed leaker" and "sound." The use of the term "assumed sound" has been informally adopted by the Department of Energy. The report "Tank Leak Assessment Process: Technical Background" [Eppel, 1998] provides the technical background for the statistical analysis. The most recent application of this procedure is reported in "Leak Assessment Report for B-111," [Thompson, 1999]. This report concluded that tank B-111 did not leak in September 1998 and is not now leaking.

Prior to the adoption of the Tank Leak Assessment Process, the mechanism for declaring a tank a "leaker" was more ad-hoc and in some cases resulted in tanks being declared as leakers (and even assigned leak volumes) without quantitative evidence of any breach of integrity [Baumhardt, 1989; Welty, 1988; Eppel, 1998]. Several reports of tank leaks prior to 1981 refer to review committees, however the workings of such committees are not well documented.

\subsection{Known Leakers}

In 1989 Baumhardt reported 24 tanks for which leak volumes could be determined by measured liquid level decreases. These tanks are considered "known leakers," even though their official designation is that of "assumed leakers" [Hanlon, 1999]. These tanks and their estimated leak volumes are listed in Table 3 below [Baumhardt, 1989; Isaacson, 1981].

The estimated leak volume for SX-109 has been updated in Hanlon from the Baumhardt evaluation to <10,000 gal [Agnew, 1998; Neilsen, 1992]. Tank T-101 is now included in the Hanlon listing of tanks with confirmed liquid level decreases. The estimated leak volume for this tank is 7,500 gal [WHC 1992a]. There are additional tanks for which leak volume estimates have been updated from the Baumhardt evaluation. These are listed in Table 4 below. 
Table 3. Leak Volumes Based on Liquid Level Decreases (25 tanks)

\begin{tabular}{|c|c|c|c|}
\hline Tank & $\begin{array}{c}\text { Leak Volume } \\
\text { (gallons) }\end{array}$ & Tank & $\begin{array}{l}\text { Leak Volume } \\
\text { (gallons) }\end{array}$ \\
\hline A-103 & 5,500 & SX-115*, ${ }^{* *}$ & 50,000 \\
\hline AX -102 & 3,000 & SX-110* & 5,500 \\
\hline B-107 & 8,000 & $T-101^{* *}$ & 7,500 \\
\hline B-110 & 10,000 & T-103 & $<1,000$ \\
\hline B-201* & 1,200 & $\mathrm{~T}-106^{*}$ & 115,000 \\
\hline B-203* & 300 & $\mathrm{~T}-108$ & $<1,000$ \\
\hline B-204* & 400 & T-109 & $<1,000$ \\
\hline BY -107 & 15,100 & $\mathrm{~T}-111$ & $<1,000$ \\
\hline$C-101$ & 20,000 & TY-101 & $<1,000$ \\
\hline C-111 & 5,500 & TY-104 & 1,400 \\
\hline C-203* & 400 & U-110 & 8,100 \\
\hline $\begin{array}{c}\text { S-104 } \\
\text { SX-104 }\end{array}$ & $\begin{array}{c}24,000 \\
6,000 \\
\end{array}$ & U-112 & 8,500 \\
\hline
\end{tabular}

* Considered "atypical" leakers

** Added to list of known leakers after the Baumhardt report.

Note: Tank SX-109 was originally included as one of the 18 typical leakers in the Baumhardt report with an estimated leak volume of 5,000 gal. The leak volume estimate has subsequently be revised to $<10,000 \mathrm{gal}$ [Agnew, 1998] and is included in Table 4 below. 
Table 4. Leak Volumes Based on Factors Other Than Liquid Level Decreases (23 Tanks)

\begin{tabular}{ccc}
\hline Tank & $\begin{array}{c}\text { Baumhardt } \\
\text { Leak Volume } \\
\text { (gallons) }\end{array}$ & $\begin{array}{c}\text { Hanlon } \\
\text { Leak Volume } \\
\text { (gallons) }\end{array}$ \\
\hline A-104 & 2,500 & 500 to 2,500 \\
A-105 & 5,000 & 10,000 to 277,000 \\
B-112 & 2,000 & 2,000 \\
BX-102 & 70,000 & 70,000 \\
B-108 & 2,500 & 2,500 \\
BY-103 & $<5,000$ & $<5,000$ \\
BY-108 & $<5,000$ & $<5,000$ \\
C-110 & 2,000 & 2,000 \\
C-201 & 550 & 550 \\
C-202 & 450 & 450 \\
C-204 & 350 & 350 \\
SX-107 & $<5,000$ & $<5,000$ \\
SX-108 & 2,400 & 2,400 to 35,000 \\
SX-109* & 5,000 & $<10,000$ \\
SX-111 & 2,000 & 500 to 2,000 \\
SX-112 & 30,000 & 30,000 \\
SX-113 & 15,000 & 15,000 \\
TX-107 & 2,500 & 2,500 \\
TY-103 & 3,000 & 3,000 \\
TY-105 & 35,000 & 35,000 \\
TY-106 & 20,000 & 20,000 \\
U-101 & 30,000 & 30,000 \\
U-104 & 55,000 & 55,000 \\
& & \\
\hline
\end{tabular}

* SX-109 was originally listed by Baumhardt with an estimated leak volume of 5,000 gal based solely on surface level decrease. This volume has now been updated by other data [Agnew, 1998]

\subsection{Assumed Leakers}

The 18 "typical" leaking tanks in Table 3 above were used to estimate the total leak volume from 19 suspected leaking tanks for which liquid level decreases could not be confirmed. These 19 tanks are considered assumed leakers based on increased radioactivity in nearby ex-tank monitoring systems (i.e., dry wells and laterals). A lognormal distribution was applied to the population of 18 typical leakers identified in Table 3 which have a cumulative estimated leak volume of 125,100 gal. After a series of statistical calculations the 18 typical leakers were determined to have a mean leak volume (i.e., typical leak volume) of 7,782 gal [Jensen, 1989]. When this mean is applied to the 19 tanks identified in Table 5 a cumulative volume of 147,858 gal is calculated. After some rounding, the nineteen tanks listed in Table 5 were assessed a cumulative leak volume estimate of $150,000 \mathrm{gal}$ with individual leak volume estimates of $8,000 \mathrm{gal}$ each [Jensen, 1989, Baumhardt, 1989, and Hanlon, 1999]. 
Table 5. Suspect Leakers for which Liquid Level Decreases

Could not be Confirmed (19 Tanks) [Baumhardt, 1989]

\begin{tabular}{c} 
Suspect Leakers \\
\hline AX-104 \\
B-101 \\
B-103 \\
B-105 \\
B-111 \\
BX-101 \\
BX-110 \\
BX-111 \\
BY-105 \\
BY-106 \\
SX-114 \\
T-107 \\
TX-105 \\
TX-110 \\
TX-113 \\
TX-114 \\
TX-115 \\
TX-116 \\
TX-117 \\
\hline
\end{tabular}

\section{$4 \quad$ Leak Types}

Aside from process upsets and structural/mechanical failures, the most likely failure mechanisms for SSTs are corrosion-related. Nearly everything known about SST corrosion is inferred from laboratory simulants or Savannah River data. There exist only limited data on the exposure of in-tank coupons to PUREX, Redox and $\mathrm{BiPO}_{4}$ wastes at Hanford.

The failure mechanisms applicable to the Hanford SSTs are ranked as follows, in decreasing order of importance [Edgemon, 1996]:

(1) stress-corrosion cracking (SCC)

(2) pitting/crevice corrosion

(3) uniform corrosion

The most common, and most plausible, leakage mechanism for the Hanford SSTs is stresscorrosion cracking. SCC can occur when the tank's carbon-steel liner is exposed to aqueous solutions containing sodium hydroxide and sodium nitrate. Cracks form in and near the welds in the tank's side wall, in the weld "heat-affected zones"-a region whose width is typically two to three times the thickness of the base material and where there is an accumulation of residual stresses from the welding that occurred during the tank's construction. (The Hanford SSTs were not treated for stress relief during construction.) The strongest evidence of stress-corrosion cracking comes from the failure of Tanks \#9, $\# 10$, \#13, \#15 and \#16 at the Savannah River Site [Girdler, 1965; Poe, 1974]. Leaks in 
these tanks occurred along numerous cracks that appeared in the lower horizontal weld of the tank.

The time it takes for cracking to occur cannot be predicted; it may be anywhere from a few months to many years. A common tool for assessing SCC in the waste tanks at Hanford and Savannah River is the corrosivity factor (CF), which is the ratio of the molar concentrations of nitrate to nitrite-plus-hydroxide. In the present corrosion specifications for double shell tanks (DSTs), the CF is set below 2.5. The calculation of the CFs is based on a rough approximation of the chemistry of the primary and secondary wastes $(70 \%$ and $30 \%$, respectively) [Anantatmula, 1994]. Tables 6 and 7 summarize CFs for waste types and tanks.

Table 6. Corrosivity Factors for Primary Waste Types (Reprinted from Anantatmula, 1994)

\begin{tabular}{|c|c|c|c|}
\hline Waste Type & $\begin{array}{l}\mathrm{OH}+\mathrm{NO}_{2} \\
\text { moles/liter }\end{array}$ & $\begin{array}{c}\mathrm{NO}_{3} \\
\text { moles/liter }\end{array}$ & $\begin{array}{l}\text { Corrosivity Factor } \\
\mathrm{NO}_{3} /\left(\mathrm{OH}+\mathrm{NO}_{2}\right)\end{array}$ \\
\hline $\begin{array}{l}\text { REDOX } \\
\text { HS } \\
2 C \\
\text { OWW } \\
1 C \\
\text { EB** } \\
\text { TBP } \\
\text { CW } \\
\text { CCPLX } \\
\text { DSSF } \\
224 \\
\text { NCPLX } \\
\text { SS } \\
\end{array}$ & $\begin{array}{c}0.74 \\
1.32 \\
\text { NR } \\
\text { NR } \\
0.56 \\
0.57 \\
0.09 \\
0.37 \\
0.52 \\
6.05 \\
0.59 \\
2.2 \\
5.74 \\
\end{array}$ & $\begin{array}{c}4.83 \\
2.1 \\
1.27 \\
0.06 \\
1.54 \\
17.26 \\
7.35 \\
0.02 \\
0.72 \\
2.72 \\
1.06 \\
3.3 \\
\text { NR } \\
\end{array}$ & $\begin{array}{c}6.53 \\
1.59 \\
5^{*} \\
1^{*} \\
2.75 \\
30.28 \\
81.67 \\
0.05 \\
1.38 \\
0.45 \\
1.8 \\
1.5 \\
0.04^{*}\end{array}$ \\
\hline
\end{tabular}


Table 7. Waste Grouping vs. Leak Status and Corrosivity Factor (Reprinted from Anantatmula, 1994)

\begin{tabular}{|c|c|c|c|}
\hline $\begin{array}{l}\text { Waste Group/ } \\
\text { Waste Type }\end{array}$ & Tanks & $\begin{array}{l}\text { Percent } \\
\text { Leaked }\end{array}$ & CF \\
\hline TBP, EB-ITS & BY-109, BY-102* & 0 & 67.67 \\
\hline $\mathrm{CW}, \mathrm{TBP}$ & $\mathrm{C}-102, \mathrm{C}-105$ & 0 & 24.54 \\
\hline SS, TBP & C-103, C-106 & 0 & 24.53 \\
\hline $\mathrm{EB}, \mathrm{CW}$ & $\underline{\mathrm{U}-105}, \underline{\mathrm{U}-107}, \mathrm{U}-108, \underline{\mathrm{U}-109}$ & 0 & 21.21 \\
\hline $\mathrm{CW}$ & U-201, U-202, U-203 & 0 & 0.05 \\
\hline EB, TBP & TX-108, TX-118 & 0 & 45.70 \\
\hline REDOX, EB & 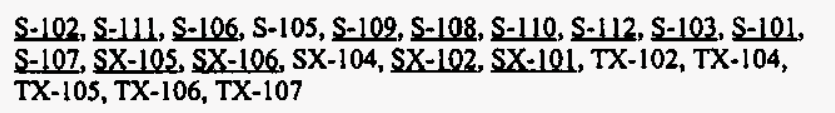 & 14 & 13.66 \\
\hline EB, REDOX & $\mathrm{U}-103, \mathrm{U}-102, \mathrm{U}-111, \mathrm{U}-106, \mathrm{TX}-115$ & 20 & 23.16 \\
\hline IC, EB & B-107, B-108, B-109, BX-112 & 25 & 11.01 \\
\hline DSSF, NCPLX & A-101, A-102, A-103, AX-101 & 25 & 0.77 \\
\hline $2 C, 224$ & $\mathrm{~T}-110, \mathrm{~T}-111, \mathrm{~T}-112$ & 33 & 4.04 \\
\hline 224 & B-201, B-202, B-203, B-204, T-201, T-202, T-203, T-204 & 37.5 & 1.80 \\
\hline Ungrouped & $\begin{array}{l}\text { A-104, A-105, A-106, AX-104, B-104, BX-109, C-104, C-107, SX-103, } \\
\text { T-109, T-104, TX-101, TX-103, TX-112, TY-101, U-110, U-112, U-204 }\end{array}$ & 39 & $\begin{array}{l}0.85 \text { for C-107; } \\
4.87 \text { for } \\
\text { SX-103; } \\
2.75 \text { for T-104 }\end{array}$ \\
\hline TBP-F, IC & C-108, C-109, C-111, C-112, T-107 & 40 & 35.83 \\
\hline TBP, CW & BX-101, BX-102, BX-103, BX-104, BX-105, BX-106, C-101 & 43 & 57.18 \\
\hline TBP-F, EB-ITS & $\begin{array}{l}\text { BY-101, BY-103, BY-104, BY-105, BY-106, BY-107, BY-108, } \\
\text { BY-110, BY-111, BY-112 }\end{array}$ & 50 & 45.5 \\
\hline CCPLX, DSSF & $\mathrm{AX}-102, \mathrm{AX}-103$ & 50 & 1.10 \\
\hline $1 \mathrm{C}, \mathrm{CW}$ & $T-105, T-106$ & 50 & 1.94 \\
\hline IC, TBP & B-106, BX-107, BX-108, C-110, T-108 & 60 & 26.43 \\
\hline $\mathrm{CW}, \mathrm{EB}$ & B-101, B-102, B-103 & 67 & 9.12 \\
\hline $\mathrm{CW}, \mathrm{MIX}$ & $T-101, T-102, T-103$ & 67 & 0.10 \\
\hline $\mathrm{EB}, 1 \mathrm{C}$ & $\begin{array}{l}\text { B-105, TX-109, TX-110, TX-111, TX-113, TX-114, TX-116, TX-117, } \\
\text { TY-102 }\end{array}$ & 75 & 22.02 \\
\hline REDOX & S-104, SX-107, SX-108, SX-109, SX-112, SX-115, U-101 & 100 & 6.53 \\
\hline HS & $\mathrm{C}-201, \mathrm{C}-202, \mathrm{C}-203, \mathrm{C}-204$ & 100 & 1.59 \\
\hline $2 C, 5-6$ & B-110, B-111, B-112 & 100 & 5.00 \\
\hline REDOX, REDOX-IX & SX-110, SX-111, SX-114 & 100 & 6.07 \\
\hline IC, EB-ITS & BX-110, BX-111 & 100 & 12.43 \\
\hline TBP & TY-105, TY-106 & 100 & 81.67 \\
\hline TBP, IC-F & TY-103, TY-104 & 100 & 57.99 \\
\hline REDOX, DIA & SX-113, U-104 & 100 & 4.57 \\
\hline
\end{tabular}

* Underline indicates tanks that were sound and not interim-stabilized (as of 1994). 
Temperature also plays an important role in initiating SCC. A critical temperature of $122^{\circ}$ F was discovered to be the threshold below which nitrate-assisted SCC was not observed [Ondrejcian, 1978].

While stress-corrosion cracking is expected to be the dominant failure mechanism for the Hanford SSTs, pitting/crevice corrosion cannot be discounted as a mechanism. Pits often begin at the site of manganese sulfide (MnS) precipitates prevalent in carbon steels. They result from a highly localized corrosion process that produces small-diameter holes in a solid metal structure. Once a pit begins, the local chemistry in the tank will cause it to grow. Typically, the growth rate accelerates as the pit grows deeper. Once initiated, the pitting can rapidly produce a hole in plate steels.

There are three pitting corrosion conditions postulated for SSTs:

(1) Concentration Cell Pitting

(2) Meniscus Pitting

(3) Vapor Phase Pitting

Concentration cell pitting can develop when differing waste types remain in strata, creating concentration differences resulting in significant shifts in electrochemical potential between portions of the tank wall. Under these conditions, the anodically polarized wall sections will be subject to localized attack.

In tanks with a liquid/vapor interface, meniscus pitting can occur as the carbon dioxide reaction from the ventilation air depresses the waste $\mathrm{pH}$ at the waterline. Carbon steel tank liners become vulnerable to pitting and galvanic attack at a $\mathrm{pH}$ of less than 10 .

Vapor phase pitting can occur when water vapor condenses on the tank walls, creating a dilute, low $\mathrm{pH}$ film in which carbon steel is vulnerable to pitting.

While uniform corrosion does occur in the SSTs, the corrosion rates are generally less than $1 \mathrm{mil}(0.001 \mathrm{in})$ per year. Thinning to point of failure is highly unlikely. Accordingly, SST failures due to uniform corrosion are discounted in this report.

\section{Bulging Bottoms}

Six tanks have been documented with bulged bottoms, as described in Table 8 below. Four of these tank bulges are attributed to expansion of the carbon steel liner bottom resulting from the addition of boiling wastes. Tank A-105 bulging is attributed to a steam flash between the carbon steel liner and the concrete base mat. The cause of the Tank U104 bulge is not documented.

Simple two dimensional calculations indicate that a temperature delta on the order of $160^{\circ} \mathrm{F}$ would create a thermally induced structural instability in a flat plate of A283, grade $\mathrm{C}$ mild carbon steel. Complex thermal modeling would be necessary to accurately portray the details of the steel/concrete/soil thermal interactions and combine those thermally induced stresses with the applied loads of incoming waste and the dished bottom configuration of most of the SST designs. In simple terms, tanks that received boiling 
waste (A, AX, and SX farms) may have been subjected to thermally induced loads sufficiently high to bulge (and fail) the bottoms creating a leak path between the liner and concrete to the base mat/footing construction joint.

Anecdotal reports of tank bottoms bulging in the SX tank farm while under construction and even leaking during acceptance testing have not been confirmed through documentation. The large leak rates associated with SX-110 (12 gal/hr), SX-115 (306 $\mathrm{gal} / \mathrm{hr}$ ), and T-106 (102 gal/hr) are suspect for bulging bottoms or a similar catastrophic failure.

Table 8. SSTs with Bulged Bottoms.

\begin{tabular}{ccccc}
\hline Tank & Boil Date & Leak Date & Leak Mechanism & Reference \\
\hline A-105 & Mar '63 & 1963 & Steam Expansion & RHO-R-39 \\
SX-107 & Jun '56 & 1964 & Thermal Expansion & RHO-R-39 \\
SX-108 & Jun'56 & 1962 & Thermal Expansion & RHO-R-39 \\
SX-112 & Mar '56 & 1969 & Thermal Expansion & RHO-R-39 \\
SX-113 & Apr '58 & 1958 & Thermal Expansion & RHO-R-39 \\
U-104 & $*$ & 1956 & & GE Memo \\
\hline
\end{tabular}

* Not Documented

\section{Sluicing Leaks}

Between 1952 and 1957, 43 SSTs in the B, BX, BY, C, T, TX, and U tank farms were sluiced to recover uranium and then returned to service. Between 1962 and 1978, an additional 10 tanks in the $\mathrm{A}$ and $\mathrm{AX}$ tank farms were sluiced to recover strontium and cesium. Of these, eight were returned to service; during the sluicing operations Tanks A104 and A-105 were found to be leaking and were therefore removed from service at the completion of those operations [Rodenhizer, 1987]. (Tank A-105 was sluiced after the leak had been discovered, so that high-heat-producing sludge could be removed. Tank A104 started to leak during the sluicing operations, but no definitive relationship between the leak and these operations was established [Rasmussen, 1980].) Tables 9 and 10 below list tanks and sludge volume retrieved during both strontium and cesium recovery and uranium recovery campaigns.

With respect to leaks and sluicing, 53 tanks in total have been sluiced to empty or nearly empty levels. The bulk of sluicing operations took place in tanks that held metal wastes from the bismuth-phosphate process as part of uranium recovery operations. The one tank that was identified as a leaker during sluicing operations (A-104) contained a mixture of wastes from the PUREX process and organic wash wastes [Rodenhizer, 1987 and Brevick, 1994]. By excluding tank A-105 because it was identified as a leaker prior to sluicing, 51 out of the 52 tanks that were sluiced $(98 \%)$ remained sound and were returned to service. Of the 51 tanks returned to service, $21(41 \%)$ were subsequently declared "assumed leakers." The remaining 30 tanks that have been sluiced and that have not had indications of leaks may be candidate tanks for early hydraulic retrieval. 
Table 9. Strontium and Cesium Recovery Sluicing Campaigns

\begin{tabular}{ccc}
\hline Tank ID & Sluicing Period & Sludge Volume Retrieved (Kgal) \\
\hline A-101 & $1968-1976$ & 107 \\
A-102 & $1964-1976$ & 170 \\
A-103 & $1962-1976$ & 116 \\
A-104 & $1969-1975$ & 223 \\
A-105 & $1968-1970$ & 147 \\
A-106 & $1969-1977$ & 237 \\
AX-101 & $1975-1976$ & 66 \\
AX-102 & 1976 & 66 \\
AX-103 & $1976-1977$ & 82 \\
AX-104 & 1977 & 52 \\
\hline
\end{tabular}

Table 10. Uranium Recovery Sluicing Campaigns

\begin{tabular}{|c|c|c|}
\hline Tank ID & Sluicing Period & Sludge Volume Retrieved (Kgal) \\
\hline U-101 & $1952-1956$ & 132.5 \\
\hline U-102 & $1953-1957$ & 59.6 \\
\hline U-103 & $1952-1956$ & $0+132.5$ (from U-101) \\
\hline U-104 & $1953-1956$ & 132.5 \\
\hline $\mathrm{U}-105$ & $1953-1957$ & 59.6 \\
\hline U-106 & 1956 & 0 \\
\hline U-107 & $1953-1957$ & 132.5 \\
\hline U-108 & $1953-1956$ & 59.6 \\
\hline U-109 & $1953-1956$ & 0 \\
\hline C-101 & $1952-1953$ & 132.5 \\
\hline C- 102 & 1953 & 59.6 \\
\hline C-103 & 1953 & 0 \\
\hline C-104 & $1953-1955$ & 132.5 \\
\hline C- 105 & 1953 & 59.6 \\
\hline C-106 & $n / a$ & 0 \\
\hline C-201 & 1954 & 16 \\
\hline C-202 & 1954 & 8 \\
\hline C-203 & 1954 & 0 \\
\hline C-204 & $1954-1955$ & 0 \\
\hline B-101 & 1953 & 132.5 \\
\hline B-102 & 1953 & 59.6 \\
\hline B-103 & $\mathbf{n} / \mathbf{a}$ & 0 \\
\hline BX-101 & $1953-1954$ & 280 \\
\hline BX-102 & 1954 & 134 \\
\hline BX-103 & 1954 & 33 \\
\hline BX-104 & $1954-1955$ & 181.5 \\
\hline BX-105 & 1955 & 89 \\
\hline BX-106 & 1955 & 12.5 \\
\hline BY-101 & 1954 & 0 \\
\hline BY-102 & 1954 & 0 \\
\hline BY-103 & 1954 & 0 \\
\hline BY-104 & $\mathrm{n} / \mathrm{a}$ & 0 \\
\hline BY-105 & 1954 & - \\
\hline BY-106 & $\mathbf{n} / \mathbf{a}$ & - \\
\hline BY-111 & 1955 & - \\
\hline BY-112 & 1955 & - \\
\hline $\mathrm{T}-101$ & $1954-1956$ & 132.5 \\
\hline $\mathrm{T}-102$ & $1953-1956$ & 59.6 \\
\hline T-103 & $1953-1957$ & 0 \\
\hline
\end{tabular}




\begin{tabular}{lcc} 
TX-101 & $1954-1956$ & 259 \\
TX-102 & $1954-1956$ & 121 \\
TX-103 & 1954 & 0 \\
TX-104 & $1954-1956$ & 0 \\
TX-105 & $1954-1957$ & 91 \\
TX-106 & 1955 & - \\
TX-107 & $1954-1957$ & - \\
TX-108 & $1954-1957$ & - \\
\hline
\end{tabular}

\subsection{Catastrophic Leaks (Greater than 50,000gal)}

Catastrophic failure, defined in this analysis as either structural collapse or the loss of 50,000 gal or more, has a relatively low (albeit unquantified) probability of occurrence. Catastrophic "leak rates" were also defined in Isaacson 1981 as leak rates greater than 10 $\mathrm{gal} / \mathrm{hr}$. As described in section 4, catastrophic leaks are associated more with process and operational upsets than with static storage conditions. Table 11 presents information on the seven tanks known to have leaked according to these definitions. Five tanks, meet the leak volume definition, five tanks meet the leak rate definition, and three tanks meet both definitions. No SSTs have suffered structural collapse.

Table 11. Catastrophic Leaks in SSTs

\begin{tabular}{ccccc}
\hline Tank & Date & Age of Tank (Years) & Volume (gal) & Rate (gal/h) \\
\hline A-105 & 1963 & 6 & 10,000 to 277,000 & 0.3 to $6(\mathrm{a})$ \\
BX-102 & 1971 & 21 & 70,000 & $1(\mathrm{~b})$ \\
SX-110 & 1976 & 22 & 5,500 & $12(\mathrm{c})$ \\
SX-113 & 1962 & 8 & 15,000 & $55(\mathrm{~d})$ \\
SX-115 & 1965 & 5 & 50,000 & $306(\mathrm{c})$ \\
T-106 & 1973 & 26 & 115,000 & $102(\mathrm{c})$ \\
U-104 & 1961 & 12 & 55,000 & $140(\mathrm{e})$ \\
\hline
\end{tabular}
a) Leak rate estimated from Leak Data Basis Review narrative, Section 5.
b) Leak rate referenced in Womack, 1971
c) Leak rate referenced in Isaacson, 1981
d) Leak rate referenced in Hanson, 1962
e) Leak rate estimated from Roberts, 1961

There is no compelling reason to expect catastrophic failure of the interim-stabilized tanks during the interim period before retrieval. Minimizing catastrophic failures during retrieval operations will depend largely on the response time necessary to declare a leak and the ability of in-tank equipment to remove free liquids.

\subsection{Concrete Stability}

Both tank concrete core samples and representative concretes prepared in the laboratory have been tested to evaluate the structural integrity of single and double shell tanks. Thermal expansion rate studies and mechanical property tests have been conducted on concrete core samples from tank domes in A Farm and T Farm. Core samples from the sidewall of tank SX-115 have been tested for mechanical properties. Although some 
cracking has been observed in the haunch and cylinder of the tank concrete, no in-service thermal, chemical, or loading mechanism has been identified that would lower the concrete structural properties to below the minimum initial design strengths [DeFigh-Price, 1980 and 1981; Vollert, 1979].

\section{$5 \quad$ Leak Data Basis Review}

This section provides a summary of the information forming the basis for the declaration of individual tank leaks. Specific references to original documentation such as occurrence reports and leak investigations are cited where possible. It is important to note that for roughly one-third of the 67 SSTs identified as assumed leakers, only summary information (i.e., no original reference) is available through the standard document control and archive systems. Where no tank specific reference is cited, the majority of the summary information came from Welty, 1988 and Brevick, 1993.

Additional tank specific data is tabulated in Appendix A. Analyses, investigations, historical reports, and historical correspondence is reprinted in Volume II.

\section{A Farm}

The A Farm comprises six 100 series, 1,000,000 gal, $75 \mathrm{ft}$ diameter tanks originally designed to provide storage for aging wastes from PUREX. The A farm was a fourth generation flat bottom design intended to store self-boiling wastes with temperatures up to $250^{\circ} \mathrm{F}$. Leak detection capabilities for these tanks consist of dry wells near each tank and laterals that extend along an underlying plane $10 \mathrm{ft}$ below the tank bottoms. Most A Farm dry wells were deepened to 125 feet in 1978.

\section{A-103}

Tank 103-A was declared an assumed leaker in 1987 based on liquid level calculations. This tank had been reclassified from Active/Sound to Sound/Deactivated in August 1980.

No radiation peaks have been observed in laterals under this tank. Dry wells at both the northeast and southwest quadrants around this tank (10-03-01 and 10-03-07) have shown radiation peaks at or below the tank bottom since 1964. Activity at dry well 10-03-07 increased significantly between February 1968 and September 1969. In May 1978 dry well 10-03-01 developed a peak which was associated with the transport of existing activity by a 60,000 gal raw water (uncontaminated) leak to the ground in February 1978. A sluicing pump was installed in this tank in 1976. Sluicing was completed in November 1976 , after which time the tank became a DSSF waste receiver for the 242-A Evaporator.

A surface level decrease in December 1979 was attributed crust slumping (Occurrence Report 79-118). A surface level decrease in September 1980 was attributed to mixing of dissimilar solids within the tank (Occurrence Report 80-82). A surface level decrease in April 1981 was attributed to slurry growth followed by crust collapse (Limit Deviation Report 81-02). Dry wells and laterals remained stable during all of these events.

This tank is one of 24 tanks for which the leak volume estimate is based solely on liquid level calculations. It is also one of the 18 "typical" tanks used to estimate leak volume for 
19 other SSTs with assumed leaks that could not be estimated by surface level measurements. The estimated leak volume for A-103 is 5,500 gal.

\section{A-104}

Tank A-104 was classified as a confirmed leaker in April 1975 and pumped down to a sludge heel (Occurrence Report 75-39). It was classified as interim-stabilized in 1984. Confirmation of the leakage was based on activity in the laterals underneath the tank (Occurrence Report 75-39). At the time of the leak, the tank was being sluiced and contained approximately 60,000 gal of waste. A preliminary estimate of the volume of waste released was set at 5,000 gal. Subsequent gamma logging, neutron logging, and sediment conductivity measurements have placed the leak volume at between 1,200 to 1,500 gal. These studies also placed the actual leak date as February 1975. It is believed that a crack developed in the bottom of the northwest quadrant of the tank, where activity was first found in the soil near the center lateral.

\section{A-105}

Tank A-105 was built in 1955, containing approximately 18 in water until it was placed into service in 1962. In May 1962, 330,000 gal of supernate were added to the tank. In January 1963 thermally hot condensate waste was added to prepare the tank for the addition of PUREX self-boiling waste. Tank wastes reached boiling temperature in March 1963. In September 1963, the waste level rose 12 in (33,000 gal). It is now believed that steam was forming under the tank liner and deforming it upward [Neilsen, 1991].

The tank was suspected of leaking in November 1963 when activity was detected in one lateral. The tank level had been raised from 260 in to 280 in July 1963. It was concluded that the tank had developed a side wall leak between the elevations of 260 to $280 \mathrm{in}$. The waste level was lowered to 260 and activity in the lateral slowly decreased. Due to a lack of other storage space, the tank was allowed to refill to the suspected leak zone by October 1964. No further leakage was detected, so the tank was filled to capacity in December 1964. A steam release occurred in January 1965, pushing steam out a riser in Tank A-103. This release contaminated the area around the tank, but no leakage was indicated until March 1965, when activity in a lateral again increased. Investigations following the steam release determined that the tank bottom had bulged upward approximately $8 \mathrm{ft}$, creating a void space volume of approximately 80,000 gal. The tank remained unchanged until April 1967 , when surface level fluctuations began to occur. It was concluded that the fluctuations were caused by collapse and re-growth of a steam bubble in the void space below the tank bottom. The tank was sluiced and pumped down to the 35 in waste level by August 1968. At this time it was concluded that the tank bottom had ruptured and the void space contained a significant amount of sludge. Further investigations have disputed the sludge leak volume estimate, because activities and temperatures in the tank laterals have remained comparatively low.

Estimated leak volumes for this tank range from 10,000 gal to 277,000 gal, with much of the uncertainty for the larger volume coming from uncertainty in estimating how much of 610,000 gal of cooling water added was lost to evaporation. The initial event is estimated to have leaked a lower bound 10,000 to 45,000 gal. 


\begin{abstract}
AX Farm
The AX Farm comprises four 100 series, $1,000,000$ gal, $75 \mathrm{ft}$ diameter tanks originally designed to provide storage for aging wastes from PUREX and B Plant. The AX farm was a fifth generation design intended to store self-boiling wastes with temperatures up to $250^{\circ} \mathrm{F}$. The AX Farm has a grid of drain slots below each liner for leak detection and no overflow lines between tanks. They were in service from 1963 to 1980 . Leak detection capabilities for these tanks include dry wells, but no laterals are present in this farm. Any leakage from an AX Farm tank is captured first by a pattern of drainage slots in the concrete base pad and then in an adjacent leak detection pit. Although AX-102 and AX104 are classified as assumed leakers, no definitive evidence has been found indicating a tank breach [Hendrickson, 1997].
\end{abstract}

\title{
AX-102
}

Tank AX-102 was reclassified from Active/Sound to Sound/Deactivated in September 1980. It was declared an assumed leaker in 1988 on the basis of liquid level decreases that could not be attributed to evaporation. The tank contained 184,000 gal of water until late 1966 , when it was filled to 833,000 gal with Organic Wash Waste. In early 1969 , the tank was flushed and preheated for B Plant and PUREX wastes. Two occurrence reports were written in April 1975 discussing increased activity in dry well 11-02-11 at the $55 \mathrm{ft}$ level. In May 1975 the tank was pumped to a minimum heel. The contamination was subsequently attributed to leakage from the tank's 20 in direct buried vapor line at the point where it joined the vessel vent system header. In late 1975 an asphalt sealant was injected into the soil to stabilize the activity and seal the vent header leak. The tank was subsequently refilled to the 282 in level with B Plant waste. An increase in activity in the AX-102 leak detection pit in December 1977 was attributed to evaporation of water in the pit. A similar activity increase in May 1979 was attributed to improper instrument settings (Deviation Report 79-6).

This tank is one of 24 tanks for which the leak volume estimate is based solely on liquid level calculations. It is also one of the 18 "typical" tanks used to estimate leak volume for 19 other SSTs with assumed leaks that could not be estimated by surface level measurements. The estimated leak volume for $\mathrm{AX}-102$ is 3,000 gal.

\section{AX-104}

Tank AX-104 was formerly classified as Questionable Integrity in November 1977 based on increasing activity in dry well 11-04-08 (Occurrence Report 77-202). Previous (1975) activity detected in dry well 11-04-11 had been attributed to a leak in the tank's 20 in vapor line at points above the tank and connected to the 24 in vent header. Occurrence Report 76-08 was issued in January 1976 based on increased dry well activity that was subsequently attributed to the same vapor header leak. The tank's integrity was questioned because it is unlikely that activity from the vapor header leak could be transported to dry well 11-04-08 without passing through dry well 11-04-10, which remained uncontaminated.

Tank AX-104 is one of 19 tanks grouped together (see Table 5) to estimate a cumulative leak volume based on the assumption that their mean leak volume was approximately the same as the mean leak volume for 18 tanks which were considered to be "typical leakers". 
The 18 typical leakers were determined to have a mean estimated leak volume of 7,782 gal. After some rounding, this group of 19 tanks were assessed a cumulative leak volume estimate of $150,000 \mathrm{gal}$ with individual leak volume estimates of 8,000 gal each [Jensen, 1989, Baumhardt, 1989, and Hanlon, 1999].

\section{B Farm}

The B Farm comprises twelve 100 series, 530,000 gal, $75 \mathrm{ft}$ diameter tanks and four 200 series, 54,000 gal, $20 \mathrm{ft}$ diameter tanks built between 1943 and 1944. These are first generation tanks designed to store non-boiling wastes with temperatures up to $220^{\circ} \mathrm{F}$. Leak detection capabilities for these tanks consist of dry wells only. No laterals are present in B Farm. All tanks in B Farm are Interim Stabilized and Isolated. All are classified as interim-stabilized tanks.

\section{B-101}

Tank B-101 was classified as Questionable Integrity in 1974, as soon as dry wells 20-0101 and 20-01-07 were installed. Activity was detected at the 40 to $50 \mathrm{ft}$ level. This tank was first filled with Metal Waste in 1945. Dry well 20-01-06 was installed in 1975. This dry well indicated soil contamination beginning at the top of the tank liner, apparently from an old leak or spill. Dry wells are the only means of leak detection for this tank, as the waste surface is solid and the FIC level gauge has been placed in intrusion mode.

Tank B-101 is one of 19 tanks grouped together (see Table 5) to estimate a cumulative leak volume based on the assumption that their mean leak volume was approximately the same as the mean leak volume for 18 tanks which were considered to be "typical leakers". The 18 typical leakers were determined to have a mean estimated leak volume of 7,782 gal. After some rounding, this group of 19 tanks were assessed a cumulative leak volume estimate of $150,000 \mathrm{gal}$ with individual leak volume estimates of $8,000 \mathrm{gal}$ each [Jensen, 1989, Baumhardt, 1989, and Hanlon, 1999].

\section{B-103}

Tank B-103 was first used to store Metal Waste in late 1945. It was classified as Questionable Integrity in 1978 because of unexplained activity at the tank base in dry wells 20-03-03 and 20-03-06. Liquid level decreases prior to January 1975 were attributed to moisture removed by active tank ventilation.

Tank B-103 is one of 19 tanks grouped together (see Table 5) to estimate a cumulative leak volume based on the assumption that their mean leak volume was approximately the same as the mean leak volume for 18 tanks which were considered to be "typical leakers". The 18 typical leakers were determined to have a mean estimated leak volume of 7,782 gal. After some rounding, this group of 19 tanks were assessed a cumulative leak volume estimate of $150,000 \mathrm{gal}$ with individual leak volume estimates of 8,000 gal each [Jensen, 1989, Baumhardt, 1989, and Hanlon, 1999].

\section{B-105}

Tank B-105 began operation in 1947 and was filled with second cycle waste from tank B104 via the cascade line by August 1947. Tank B-105 was classified as an assumed leaker in 1978 because of unexplained activity in dry wells 20-05-06 and 20-06-06. 
Tank B-105 is one of 19 tanks grouped together (see Table 5) to estimate a cumulative leak volume based on the assumption that their mean leak volume was approximately the same as the mean leak volume for 18 tanks which were considered to be "typical leakers". The 18 typical leakers were determined to have a mean estimated leak volume of 7,782 gal. After some rounding, this group of 19 tanks were assessed a cumulative leak volume estimate of 150,000 gal with individual leak volume estimates of 8,000 gal each [Jensen, 1989, Baumhardt, 1989, and Hanlon, 1999].

\section{B-107}

Tank B-107 was filled with First Cycle waste from May 1945 to October 1945. The tank was classified as Questionable Integrity in 1969 due to an unexplained liquid level decrease. In 1973 it was reclassified as a suspect leaker. In 1980 it was designated as an assumed leaker.

This tank is one of 24 tanks for which the leak volume estimate is based solely on liquid level calculations. It is also one of the 18 "typical" tanks used to estimate leak volume for 19 other SSTs with assumed leaks that could not be estimated by surface level measurements. The estimated leak volume for B-107 is 8,000 gal.

\section{B-110}

Tank B-110 was filled with Second Cycle waste from 1945 to 1952 . The tank was first suspected as a leaker in 1970, and classified as a suspect leaker in 1973 due to an unexplained liquid level drop. In 1981 it was reclassified as a confirmed leaker.

This tank is one of 24 tanks for which the leak volume estimate is based solely on liquid level calculations. It is also one of the 18 "typical" tanks used to estimate leak volume for 19 other SSTs with assumed leaks that could not be estimated by surface level measurements. The estimated leak volume for B-110 is $10,000 \mathrm{gal}$.

\section{B-111}

Tank B-111 was filled with Second Cycle waste from 1945 to 1946 . The tank was characterized as Questionable Integrity in 1978 due to unexplained activity in dry wells 2011-09 and 20-12-06. This activity has subsequently been attributed to transfer line leakage.

Tank B-111 is one of 19 tanks grouped together (see Table 5) to estimate a cumulative leak volume based on the assumption that their mean leak volume was approximately the same as the mean leak volume for 18 tanks which were considered to be "typical leakers". The 18 typical leakers were determined to have a mean estimated leak volume of 7,782 gal. After some rounding, this group of 19 tanks were assessed a cumulative leak volume estimate of 150,000 gal with individual leak volume estimates of 8,000 gal each [Jensen, 1989, Baumhardt, 1989, and Hanlon, 1999].

The leak status of B-111 was re-evaluated in 1999 due to an unexplained liquid level drop in a Liquid Observation Well. The expert team agreed that the evidence suggested that tank B-111 was not leaking at the time and that based on the preponderance of evidence available, it was not likely that the tank leaked in September 1998. [Thompson, 1999]. 


\section{B-112}

Tank B-112 was filled with Second Cycle waste in 1946. The tank was characterized as Questionable Integrity in 1978 due to unexplained activity in dry wells 20-12-03 and 2012-06. At the time activity was detected in the dry well, the liquid surface of this tank was being monitored. The leak volume estimate was placed at 2,000 gal because it was considered unreasonable to assume that more than 2,000 gal could leak without a surface level decrease.

\section{B-201}

Tank B-201 began filling with 224 waste in 1952 and was actively cascading to a crib. In 1971 it was classified as questionable integrity because of a slow unexplained liquid level decrease and increasing activity in dry well 20-00-01. A liquid level decrease in 1974 exceeded the allowable limit, and the remaining supernatant was removed. This tank is one of 24 tanks for which the leak volume estimate is based solely on liquid level calculations. The estimated leak volume for B-201 is 1,200 gal. The tank was classified as an assumed leaker in 1980. This tank has no dry wells or liquid observation well. Operating Limit Deviation Report 82-04 was issued in 1982 when the liquid level dropped more than 1 in. Subsequent photographs in 1982 confirmed that a liquid level decrease had occurred. Photographs taken in 1986 show a higher surface level than the previous photographs. Intrusions are believed to be masking any further tank leakage.

\section{B-203}

Tank B-203 was filled with 224 waste in 1952. This tank is one of 24 tanks for which the leak volume estimate is based solely on liquid level calculations. The estimated leak volume for B-203 is 300 gal. Photographs taken between 1978 and 1981 indicate a slow surface level decrease. Operating Limit Deviation Report 82-08 was issued in 1982 because the surface level exceeded the decrease criterion. The tank was declared a confirmed leaker in 1983 based on recommendations made by a peer review team. This tank has no liquid observation wells or dry wells.

\section{B-204}

Tank B-204 was filled with 224 waste in 1952. Environmental Protection Deviation report 83-02 was issued in 1983 when evidence was found of a liquid level decrease while conducting a classification study. The tank was reclassified to assumed leaker in 1984, based on recommendations of a peer review team. This tank is one of 24 tanks for which the leak volume estimate is based solely on liquid level calculations. The estimated leak volume for B-204 is $400 \mathrm{gal}$.

\section{BX Farm}

The BX farm comprises twelve 100 series, 530,000 gal, $75 \mathrm{ft}$ diameter tanks constructed between 1946 and 1947. These tanks have an operating depth of $17 \mathrm{ft}$. Tanks BX-101 through BX-106 received B Plant metal waste and tanks BX-107 through BX-112 received B Plant first cycle waste and cell 23 concentrator waste. Tank integrity surveillance methods consist of liquid observation wells, surface level measurements, and 76 dry wells.

\section{BX-101}

Tank BX-101 was first filled with metal waste in 1948. It was classified as questionable integrity in 1972 based on unexplained activity in dry well 21-01-01. At least part of the 
extensive activity in this dry well is attributed to a leaking pump riser. In-tank photographs have confirmed surface level increases from intrusions. A leaking diversion box drain has been identified as the cause of the intrusions. The drain has been relocated. This tank received an inadvertent transfer of approximately 1,800 gal of organic ion exchange resin in 1972.

Tank BX-101 is one of 19 tanks grouped together (see Table 5) to estimate a cumulative leak volume based on the assumption that their mean leak volume was approximately the same as the mean leak volume for 18 tanks which were considered to be "typical leakers". The 18 typical leakers were determined to have a mean estimated leak volume of 7,782 gal. After some rounding, this group of 19 tanks were assessed a cumulative leak volume estimate of 150,000 gal with individual leak volume estimates of 8,000 gal each [Jensen, 1989, Baumhardt, 1989, and Hanlon, 1999].

\section{BX-102}

Tank BX-102 was first filled with metal waste in 1948. The tank was held static at 22 in of waste between 1957 and 1962. Between 1962 and 1968 the tank was held static at maximum capacity, then returned to active service in 1969. Between 1959 and 1969 an increase in activity was observed in dry well 61 . This was attributed to a 30,000 gal to 90,000 gal spill of first cycle bismuth-phosphate waste in 1951 between tanks BX-102 and BX-103. There is some spectra gamma logging indication that in fact, this spill was metal waste instead of first cycle waste. In 1969, readings in dry well 61 were trending downward until about the time the tank was returned to active service, at which time they increased sharply. In 1970 the tank was classified as questionable integrity, pumped to a minimum heel of 22 in and removed from service. Readings in dry well 61 have decreased steadily since that time. Nineteen additional dry wells were drilled to determine the extent of the contamination. The pattern of contamination revealed by these dry wells indicate that the tank's concrete shell failed near dry well 27 (southeast tank quadrant, near the tank footing approximately $40 \mathrm{ft}$ below grade) and that $31,000 \mathrm{ft}^{3}$ of soil has been wetted by the leak. This estimated volume of contaminated soil and an assumed soil porosity of $30 \%$ yield the currently estimated leak volume of 70,000 gal. Liquid level measurements in the tank provide inconclusive evidence of a leak. It is believed that the tank failed by pitting corrosion at the 22 in level, where the tank waste was held static for 5 years.

\section{BX-108}

Tank BX-108 was filled with first cycle waste in 1949. The tank was declared a suspect leaker in the fourth quarter of 1973 based on a 0.9 in level drop indication between March 1973 and July 1973. The validity of these level drop data is questionable because of the developmental status of newly installed Food Instrument Corporation gauges and problems with their calibration. An additional 0.9 in level drop was reported between July 1973 and March 1974. This level drop forms the basis of the current 2,500 gal leak volume estimate. Dry well 21-08-06 showed increased activity in March 1974, and all residual supernate was removed by the third quarter of 1976 [Burton, 1974].

\section{BX-110}

Tank BX-110 was filled with first cycle waste in January 1950. By 1970 the integrity of the tank was questionable, based increased activity in area dry wells. 
Tank BX-110 is one of 19 tanks grouped together (see Table 5) to estimate a cumulative leak volume based on the assumption that their mean leak volume was approximately the same as the mean leak volume for 18 tanks which were considered to be "typical leakers". The 18 typical leakers were determined to have a mean estimated leak volume of 7,782 gal. After some rounding, this group of 19 tanks were assessed a cumulative leak volume estimate of 150,000 gal with individual leak volume estimates of 8,000 gal each [Jensen, 1989, Baumhardt, 1989, and Hanlon, 1999].

\section{BX-111}

Tank BX-111 was filled with first cycle waste in 1950. The tank was categorized as questionable integrity in 1978 based on increased activity in area dry wells. The tank classified as a re-leaker in 1993 based on an unexplained surface level decrease.

Tank BX-111 is one of 19 tanks grouped together (see Table 5) to estimate a cumulative leak volume based on the assumption that their mean leak volume was approximately the same as the mean leak volume for 18 tanks which were considered to be "typical leakers". The 18 typical leakers were determined to have a mean estimated leak volume of 7,782 gal. After some rounding, this group of 19 tanks were assessed a cumulative leak volume estimate of 150,000 gal with individual leak volume estimates of 8,000 gal each [Jensen, 1989, Baumhardt, 1989, and Hanlon, 1999].

\section{BY Farm}

The BY Farm contains twelve, second generation, 100 series single shell tanks constructed between 1948 and 1949. Each tank is $75 \mathrm{ft}$ in diameter, has an operating depth of $23 \mathrm{ft}$ and can contain up to 758,000 gal. The tanks were designed for non-boiling wastes with a maximum temperature of $220^{\circ} \mathrm{F}$.

\section{BY-103}

Tank BY-103 was filled with metal waste in 1951. The tank was classified as an assumed leaker in 1973 and was removed from service with an estimated leak volume of approximately $5,000 \mathrm{gal}$. The basis for removing the tank from service was an observed increase in activity in dry well 22-03-09. Liquid level data for this tank provide inconclusive evidence of a leak because of the number of intrusions of rainwater and snowmelt.

\section{BY-105}

Tank BY-105 was filled with metal waste in 1951. The tank was removed from service as an assumed leaker in 1974 based on increasing activity in area dry wells. In 1966, 19 tons of Portland cement were added to this tank to test the cement's properties as an immobilization agent for liquid waste. Dry wells are the only means of leak detection for this tank.

Tank BY-105 is one of 19 tanks grouped together (see Table 5) to estimate a cumulative leak volume based on the assumption that their mean leak volume was approximately the same as the mean leak volume for 18 tanks which were considered to be "typical leakers". The 18 typical leakers were determined to have a mean estimated leak volume of 7,782 gal. After some rounding, this group of 19 tanks were assessed a cumulative leak volume 
estimate of 150,000 gal with individual leak volume estimates of 8,000 gal each [Jensen, 1989, Baumhardt, 1989, and Hanlon, 1999].

\section{BY-106}

Tank BY-106 began to receive first cycle waste in 1953. The tank was removed from service as having questionable integrity in 1977 , based on increasing activity in area dry wells. Dry well 22-05-05 has shown activity migrating from $31 \mathrm{ft}$ in 1972 to $63 \mathrm{ft}$ in 1983 . Dry wells are the primary means of leak detection for this tank.

Tank BY-106 is one of 19 tanks grouped together (see Table 5) to estimate a cumulative leak volume based on the assumption that their mean leak volume was approximately the same as the mean leak volume for 18 tanks which were considered to be "typical leakers". The 18 typical leakers were determined to have a mean estimated leak volume of 7,782 gal. After some rounding, this group of 19 tanks were assessed a cumulative leak volume estimate of $150,000 \mathrm{gal}$ with individual leak volume estimates of 8,000 gal each [Jensen, 1989, Baumhardt, 1989, and Hanlon, 1999].

\section{BY-107}

Tank BY-107 was filled with first cycle waste in 1951. The tank was classified as questionable integrity in 1974, based on unexplained liquid level decreases. Increasing activity in area dry wells has been attributed to movement of soil contamination from other sources. Intrusion prevention was completed in 1982, but subsequent in-tank photographs show more surface liquid than previous photos.

This tank is one of 24 tanks for which the leak volume estimate is based solely on liquid level calculations. It is also one of the 18 "typical" tanks used to estimate leak volume for 19 other SSTs with assumed leaks that could not be estimated by surface level measurements. The estimated leak volume for BY-107 is 15,100 gal.

\section{BY-108}

Tank BY-108 was filled with first cycle waste from the BY-107 cascade between 1951 and 1953. The tank was classified as an assumed leaker in 1972, with an estimated leak volume of approximately 5,000 gal. Dry wells 22-08-02 and 22-08-12 showed increased activity in 1974. A 2,600 gal intrusion of snow melt occurred in 1980. Dry wells are the only means of leak detection available for this tank.

\section{Farm}

The C Farm comprises twelve first generation, 100 series, 530,000 gal, $75 \mathrm{ft}$ diameter tanks and four first generation, 200 series, 54,000 gal, $20 \mathrm{ft}$ diameter tanks constructed between 1943 and 1944 . The C Farm tanks were designed for non-boiling waste, with temperatures below $220^{\circ} \mathrm{F}$.

\section{C-101}

Tank C-101 was filled with metal waste in 1946. The tank was pumped to a minimum heel in 1969, following an unexplained liquid level decrease. It was classified as questionable integrity in 1970. In 1970, several new dry wells were found to be contaminated when first monitored. The tank was classified as a confirmed leaker in 1980 
based on the recommendations of a review team evaluating the recategorization of nine questionable integrity tanks. Because of solids, dry wells are now the only means of leak detection for this tank.

This tank is one of 24 tanks for which the leak volume estimate is based solely on liquid level calculations. It is also one of the 18 "typical" tanks used to estimate leak volume for 19 other SSTs with assumed leaks that could not be estimated by surface level measurements. The estimated leak volume for C-101 is 20,000 gal.

\section{C-110}

Tank C-110 was filled with first cycle waste from 1964 to 1967 . The tank was removed from service in 1976, following the discovery of unexplained activity in dry wells 30-1002 and 30-10-09. The tank was declared an assumed leaker in 1984, with an estimated leak volume of $2,000 \mathrm{gal}$.

\section{C-111}

Tank C-111 received first cycle waste beginning in August 1946. By November 1946, the tank was full and cascaded into C-112 until April 1947. The tank was classified as questionable integrity in 1968 on the basis of an unexplained liquid level decrease. The tank was removed from service in 1975 . Dry well monitoring is now the only method for leak detection in this tank.

This tank is one of 24 tanks for which the leak volume estimate is based solely on liquid level calculations. It is also one of the 18 "typical" tanks used to estimate leak volume for 19 other SSTs with assumed leaks that could not be estimated by surface level measurements. The estimated leak volume for C-111 is 5,500 gal.

\section{C-201}

Tank C-201 was filled with metal waste in 1947. The tank was removed from service in 1976 and classified as not intended for reuse. The tank was classified as an assumed leaker in 1988 with an estimated leak volume of 550 gal. This tank does not have dry wells or liquid observation wells.

\section{C-202}

Tank C-202 was filled with metal waste in 1947. It was removed from service in 1976 and classified as not intended for reuse. The tank was declared an assumed leaker in 1988 with an estimated leak volume of $450 \mathrm{gal}$. This tank does not have dry wells or liquid observation wells.

\section{C-203}

Tank C-203 was filled with metal waste in 1947. The tank was removed from service in 1976 and classified as not intended for reuse. It was declared an assumed leaker in 1984 with a leak volume of 400 gal. This tank does not have dry wells or liquid observation wells. The tank was interim isolated in 1982 . Since that time, surface level measurements have shown a decrease of approximately 3 in. Because of this, EPDR 84-03 was issued in May 1984 and a peer review team was convened to determine the integrity of the tank. This peer review resulted in the tank being declared a confirmed leaker. 
This tank is one of 24 tanks for which the leak volume estimate is based solely on liquid level calculations. It is also one of the 18 "typical" tanks used to estimate leak volume for 19 other SSTs with assumed leaks that could not be estimated by surface level measurements. The estimated leak volume for C-203 is 400 gal.

\section{C-204}

Tank C-204 was filled with metal waste in 1948. The tank was not intended for reuse by 1976 and inactive by 1977 . In 1988 the tank was classified as an assumed leaker with a leak volume of 350 gal. This tank does not have dry wells or liquid observation wells.

\section{S Farm}

The S Farm comprises twelve 100 series tanks built in 1950 and 1951. Each tank has an operating capacity of $758,00 \mathrm{gal}$, dished bottom construction, and is $75 \mathrm{ft}$ in diameter. The tanks were designed to store non-boiling waste with a maximum temperature of $220^{\circ} \mathrm{F}$.

\section{S-104}

Tank S-104 was filled with REDOX waste from 1953 to 1974 . In 1968 the tank was classified as an assumed leaker of $24,000 \mathrm{gal}$ and removed from service. The leak volume is based on an unexplained liquid level decrease. Four dry wells are the primary leak detection mechanisms now available for this tank. Tank S-104 does not have a liquid observation well and has a solid waste surface layer.

This tank is one of 24 tanks for which the leak volume estimate is based solely on liquid level calculations. It is also one of the 18 "typical" tanks used to estimate leak volume for 19 other SSTs with assumed leaks that could not be estimated by surface level measurements.

\section{SX Farm}

The SX Farm comprises fifteen 100 series, Type IV tanks constructed to the third generation design in 1953 and 1954. The construction specification was HW-4957. Each tank has an operating capacity of 1,000,000 gal, dished bottom construction, no knuckle, and is $75 \mathrm{ft}$ in diameter. The tanks have a reinforced concrete base, walls, and domed roof. The cylindrical wall and dished bottom are lined with $3 / 8$ inch carbon steel plate. The tank bottom has a radius of curvature of 569.95 feet, which forms a dish 15 inches deep. The dished bottom makes a $\mathrm{T}$-joint connection with the cylindrical wall. The steel liner is used as the inside form for the construction of the reinforced concrete wall.

The tanks were originally designed to provide storage space for self-boiling REDOX wastes. Tank contents were allowed to boil for one to five years at a temperature of up to $250^{\circ} \mathrm{F}$.

Tanks SX-101 through SX-106 began operations in 1954, receiving REDOX salt waste and first-cycle condensate waste. Tanks SX-107 through SX-115 were placed into service in 1955, receiving REDOX boiling high-level waste and salt waste. Tank leak surveillance methods for the SX tank farm include liquid observation wells, surface level measurements, dry wells, and leak detection laterals under tanks SX-105, SX-108, and SX-115. 
Anecdotal reports have suggested that some tanks in the SX Farm may have leaked during acceptance testing following construction. No confirmation of these reports has been found.

\section{SX-104}

Tank SX-104 was removed from service and labeled inactive in 1980. It is classified as an assumed leaker.

This tank is one of 24 tanks for which the leak volume estimate is based solely on liquid level calculations. It is also one of the 18 "typical" tanks used to estimate leak volume for 19 other SSTs with assumed leaks that could not be estimated by surface level measurements. The estimated leak volume for SX-104 is 6,000 gal.

\section{SX-107}

Tank SX-107 was removed from service and classified as an assumed leaker in 1964. The estimated leak volume is less than 5,000 gal.

\section{SX-108}

The first indications of a possible leak in tank SX-108 were noted in December 1962 when a small increase in activity was recorded in two laterals. Additional monitoring detected no increased activity, so the tank was kept in service. Increased activity was again detected in the laterals in August 1964, followed by the detection of activity in dry well 41$08-11$. No liquid level decrease was detected during this time, so the leak was judged to have become inactive. In 1965 the leak volume was estimated at 2,400 gal, based on soil samples and activity levels in the dry wells and laterals. In 1967 the tank was declared to be leaking based on increased activity in the laterals. The tank was subsequently taken out of service and the supernate pumped. Activity in the laterals has increased and stabilized since the 1965 leak volume estimate. It appears that the leak has continued and the underground plume has spread and moved south. Photographs taken in the tank since 1967 indicate that the leak volume may approach 33,000 gal, but heat generation data suggest that enough heat was available to evaporate this volume. Thus the total leak volume for the operating history of this tank is set at the range of 2,400 gal to 35,000 gal [Neilsen, 1992b].

\section{SX-109}

Tank SX-109 was first suspected of leaking in January 1965 when activity was detected in two laterals. By February 1965 the tank was declared a confirmed leaker. Significant increases in activity were identified in dry wells in September 1972, and the tank was pumped to a minimum level. Additional leakage has occurred since the tank was pumped. By 1992 the activity in the dry wells around the tank was stable or decreasing. Initial estimates of total leakage from the tank were 5,000 gal and 56,000 $\pm 15,000$ gal. By January 1992 the leak volume estimate had been revised to 10,000 gal, based on an approximate comparison of the size of the contaminated area under this tank and that under SX-108. [Neilsen, 1992a] 


\section{SX-110}

Tank SX-110 was classified as questionable integrity and removed from service in 1976 following an unexplained liquid level decrease (Occurrence Report 76-91). The tank now contains mostly solids, so the only available means of leak detection are dry well and lateral activity readings.

This tank is one of 24 tanks for which the leak volume estimate is based solely on liquid level calculations. It is also one of the 18 "typical" tanks used to estimate leak volume for 19 other SSTs with assumed leaks that could not be estimated by surface level measurements. The estimated leak volume for this tank is 5,500 gal.

\section{SX-111}

Tank SX-111 was classified as a confirmed leaker and removed from service in May 1974 on the basis of increased activity in center leak detection lateral 44-11-02 (Occurrence Reports 74-38 and 75-05). Neither of the other two laterals nor the dry wells have shown any increased activity. The estimated leak volume for this tank is 500 to 2,000 gal.

\section{SX-112}

Tank SX-112 was classified as a confirmed leaker and removed from service in 1969. The estimated leak volume for this tank is 30,000 gal.

\section{SX-113}

Tank SX-113 was classified as a confirmed leaker in 1962 and removed from service. In 1958 the tank bottom bulged shortly after self concentrating waste was routed to the tank [Hanson, 1962]. Although the bulge receded several days later, the integrity of the tank was in doubt, and the boiling waste was pumped to another tank. The tank bottom bulged again after these wastes were removed. This bulge also receded over a period of several days. Although the tank bottom had bulged twice, the tank laterals and area dry wells showed no increased activity. Moreover, no damage to the tank liner could be observed by internal periscopic examination. Since waste storage space was limited, it was decided to leak test this tank for potential re-use by adding liquid to the tank and attempting to observe a liquid level decrease. Leak testing of this tank was started on October 10, 1962 and terminated November 13,1962, following a liquid level decrease and an increase in activity in the laterals under the tank. It was estimated that 15,000 gal of waste was lost during the leak test at a leak rate of approximately 55 gallons per hour. The remaining contents of SX-113 were transferred to SX-114 on November 14 and 15, 1962.

\section{SX-114}

Tank SX-114 was classified as questionable integrity in 1972 and removed from service. The basis for the questionable integrity classification was unexplained activity in area dry wells.

Tank SX-114 is one of 19 tanks grouped together (see Table 5) to estimate a cumulative leak volume based on the assumption that their mean leak volume was approximately the same as the mean leak volume for 18 tanks which were considered to be "typical leakers". The 18 typical leakers were determined to have a mean estimated leak volume of 7,782 gal. After some rounding, this group of 19 tanks were assessed a cumulative leak volume 
estimate of 150,000 gal with individual leak volume estimates of 8,000 gal each [Jensen, 1989, Baumhardt, 1989, and Hanlon, 1999].

\section{SX-115}

In March 1965 a liquid level decrease over one week in tank SX-115 indicated that the tank had developed a leak. The level decrease of 18 in indicated that about 51,000 gal of waste and sodium nitrate solution had been lost. The tank was subsequently pumped, leaving approximately 8,000 gal of solids and interstitial liquid. Stress corrosion cracking of the liner by the alkaline solution was said to be the most probable cause of tank failure. Activity scans of laterals taken prior to 1965 indicate that the tank may have leaked as early as 1963 . Subsequent activity studies under the tank have accounted for approximately $60 \%$ of the leak volume in three areas of contamination from 6 to $10 \mathrm{ft}$ below the tank [Neilsen, 1992c]. In 1981, $38 \mathrm{ft} 8$ in of approximately 3 in diameter concrete core was removed from the haunch, wall and footing of this tank. The cores were tested to evaluate the long term structural integrity of single and double shell tanks [DeFigh-Price, 1981]

\section{T Farm}

The T Farm comprises twelve first generation 100 series and four 200 series dish bottom tanks built between 1943 and 1944. The 100 series tanks are $75 \mathrm{ft}$ in diameter with a capacity of 540,000 gal (tanks T-101 through T-112). The 200 series tanks are $20 \mathrm{ft}$ in diameter with a capacity of 54,000 gal (tanks T-201 through T-204). The tanks were designed to store non-boiling waste with a maximum temperature of $220^{\circ} \mathrm{F}$. These tanks were built to store wastes from $T$ Plant. The first cascade began receiving metal waste from the T Plant bismuth phosphate process in December 1944.

\section{T-101}

Tank T-101 was declared an assumed leaker in 1992 based on a liquid level decrease of 2.6 in (occurrence report RL-WHC-TANKFARM-1992-0073). This level drop forms the basis for the estimated leak volume of 7,500 gal. Tank T-101 was interim-stabilized in April 1993. Increased activity in dry wells 50-01-04, 50-01-06, and 50-00-03 has been attributed to a leak through a spare fill line caused by the tank being overfilled in an attempt to utilize the cascade line to T-102. Activity in dry well 50-01-12 has been attributed to leakage of the cascade line to tank T-102.

This tank is one of 24 tanks for which the leak volume estimate is based solely on liquid level calculations. It is also one of the 18 "typical" tanks used to estimate leak volume for 19 other SSTs with assumed leaks that could not be estimated by surface level measurements.

\section{T-103}

Tank T-103 was classified as questionable integrity and removed from service in 1974 on the basis of a liquid level decrease in excess of 0.3 in between November 1973 and February 1974. Increased activity in dry wells 50-03-04, 50-03-05, and 50-03-06 has been attributed to this tank leak. The increased activity at the $20 \mathrm{ft}$ level of dry well 50-03-04 has been attributed to past leakage form the spare fill line to T-103 resulting from overfilling the tank. 
This tank is one of 24 tanks for which the leak volume estimate is based solely on liquid level calculations. It is also one of the 18 "typical" tanks used to estimate leak volume for 19 other SSTs with assumed leaks that could not be estimated by surface level measurements. The estimated leak volume for T-103 is less than 1,000 gal.

\section{T-106}

Tank T-106 recorded level decreases of over 41 in over a period of 49 day between April 20,1973 and June 8, 1973 for a total estimated leak volume of 115,000 gal [Smith, 1973]. The tank was pumped to minimum heel in June 1973 and further pumped down to a residual layer of less than 6 in by July 1974. All of the dry wells adjacent to this tank show significant levels of activity. This leak event received significant analysis and investigation at the time. The majority of this analysis is included directly or via reference in Smith, 1973.

\section{T-107}

Tank T-107 was classified as questionable integrity in April 1976 and removed from service. The basis for this classification was increasing activity in area dry wells. Dry well 50-07-07 shows a peak activity at $42 \mathrm{ft}$, which has been slowly declining since first monitored in 1974. Dry well 50-07-03 showed a peak at $43 \mathrm{ft}$ when first monitored in 1975. This peak has been declining since September 1977.

Tank T-107 is one of 19 tanks grouped together (see Table 5) to estimate a cumulative leak volume based on the assumption that their mean leak volume was approximately the same as the mean leak volume for 18 tanks which were considered to be "typical leakers". The 18 typical leakers were determined to have a mean estimated leak volume of 7,782 gal. After some rounding, this group of 19 tanks were assessed a cumulative leak volume estimate of 150,000 gal with individual leak volume estimates of 8,000 gal each [Jensen, 1989, Baumhardt, 1989, and Hanlon, 1999].

\section{T-108}

Tank T-108 was classified as an assumed leaker and removed from service in 1974. The basis for this classification was an unexplained level decrease of more than 0.3 in. Dry wells in the area show activity, but the source of the activity has not been confirmed. A 1979 reevaluation of activity in dry well 50-08-07 concluded the activity in this dry well was migrating from the direction of tank T-106.

This tank is one of 24 tanks for which the leak volume estimate is based solely on liquid level calculations. It is also one of the 18 "typical" tanks used to estimate leak volume for 19 other SSTs with assumed leaks that could not be estimated by surface level measurements. The estimated leak volume for tank T-108 is less than 1,000 gal.

\section{T-109}

Tank T-109 was classified as an assumed leaker and removed from service in 1974. The basis for this classification was increased activity in dry well 50-09-10 starting at the $39 \mathrm{ft}$ depth. 
This tank is one of 24 tanks for which the leak volume estimate is based solely on liquid level calculations. It is also one of the 18 "typical" tanks used to estimate leak volume for 19 other SSTs with assumed leaks that could not be estimated by surface level measurements. The estimated leak volume for tank T-109 is less than 1,000 gal.

\section{T-111}

Tank T-111 was classified as an assumed leaker and removed from service in 1974. The basis for this classification is an unexplained liquid level decrease of more than 0.3 in.

This tank is one of 24 tanks for which the leak volume estimate is based solely on liquid level calculations. It is also one of the 18 "typical" tanks used to estimate leak volume for 19 other SSTs with assumed leaks that could not be estimated by surface level measurements. The estimated leak volume for tank T-110 is less than 1,000 gal.

\section{TX Farm}

The TX farm contains eighteen 100 series dish bottom tanks built between 1947 and 1948 . These tanks are $75 \mathrm{ft}$ in diameter and have a capacity of 758,000 gal. They were designed to store non-boiling wastes at temperatures up to $220^{\circ} \mathrm{F}$. The first two cascades (TX-101 through TX-108) were filled with T Plant metal waste. The third cascade (TX-109 through TX-112) stored first cycle decontamination waste before use with the 242-T evaporator. The last 6 tanks were not used until the 1950's when they were put into use as evaporator feed, bottoms, and recycle tanks.

\section{TX-105}

Tank TX-105 was removed from service in 1976 and classified as an assumed leaker in 1977. The basis for this classification was activity in 5 of the 6 dry wells associated with this tank.

Tank TX-105 is one of 19 tanks grouped together (see Table 5) to estimate a cumulative leak volume based on the assumption that their mean leak volume was approximately the same as the mean leak volume for 18 tanks which were considered to be "typical leakers". The 18 typical leakers were determined to have a mean estimated leak volume of 7,782 gal. After some rounding, this group of 19 tanks were assessed a cumulative leak volume estimate of $150,000 \mathrm{gal}$ with individual leak volume estimates of $8,000 \mathrm{gal}$ each [Jensen, 1989, Baumhardt, 1989, and Hanlon, 1999].

\section{TX-107}

Tank TX-107 was classified as inactive and questionable integrity in 1977 and confirmed leaker in 1984. Four dry wells were drilled in 1977 to determine the source of new activity in dry well 51-03-12 at the $51 \mathrm{ft}$ level. Occurrence report 77-103 concluded that increased activity in dry well 51-07-08 may have come from tank TX-107. Increasing activity in dry well 51-07-07 prompted Occurrence Report number 83-22. A peer review team study reclassified the tank from questionable integrity to confirmed leaker in May 1984. The estimated leak volume for this tank is 2,500 gal. 


\section{TX-110}

Tank TX-110 was classified as questionable integrity in 1974. In March 1974 there was a liquid level decrease of greater than 0.5 in and the tank was removed from service. An intensive 19 day study of liquid level, dry well monitoring, and psychrometric analyses provided no further explanation of the level decrease. In June 1997 new activity was observed in dry well 51-10-01 at $55 \mathrm{ft}$. Dry well 51-10-13 was drilled in an attempt to better characterize the source of the new activity (Occurrence Report 79-31). Other liquid level decreases in 1979 (Occurrence Report 70-31) and 1980 (Operating Limit Deviation Report 80-13) were attributed to measurement interference from solids.

Tank TX-110 is one of 19 tanks grouped together (see Table 5) to estimate a cumulative leak volume based on the assumption that their mean leak volume was approximately the same as the mean leak volume for 18 tanks which were considered to be "typical leakers". The 18 typical leakers were determined to have a mean estimated leak volume of 7,782 gal. After some rounding, this group of 19 tanks were assessed a cumulative leak volume estimate of $150,000 \mathrm{gal}$ with individual leak volume estimates of 8,000 gal each [Jensen, 1989, Baumhardt, 1989, and Hanlon, 1999].

\section{TX-113}

Tank TX-113 was classified as questionable integrity in 1974 (Occurrence Report 74-129) and removed from service in 1976. The basis for this classification was unexplained increased activity in area dry wells.

Tank TX-113 is one of 19 tanks grouped together (see Table 5) to estimate a cumulative leak volume based on the assumption that their mean leak volume was approximately the same as the mean leak volume for 18 tanks which were considered to be "typical leakers". The 18 typical leakers were determined to have a mean estimated leak volume of 7,782 gal. After some rounding, this group of 19 tanks were assessed a cumulative leak volume estimate of $150,000 \mathrm{gal}$ with individual leak volume estimates of $8,000 \mathrm{gal}$ each [Jensen, 1989, Baumhardt, 1989, and Hanlon, 1999].

\section{TX-114}

Tank TX-114 was classified as questionable integrity in 1974 (Occurrence Report 74-129) and removed from service in 1975. The basis for this classification was unexplained increased activity in area dry wells. All dry wells associated with this tank have activity at the $43 \mathrm{ft}$ level, with well 51-14-04 showing an extensive profile change below the $48 \mathrm{ft}$ level in 1977 and 1978.

Tank TX-114 is one of 19 tanks grouped together (see Table 5) to estimate a cumulative leak volume based on the assumption that their mean leak volume was approximately the same as the mean leak volume for 18 tanks which were considered to be "typical leakers". The 18 typical leakers were determined to have a mean estimated leak volume of 7,782 gal. After some rounding, this group of 19 tanks were assessed a cumulative leak volume estimate of $150,000 \mathrm{gal}$ with individual leak volume estimates of $8,000 \mathrm{gal}$ each [Jensen, 1989, Baumhardt, 1989, and Hanlon, 1999]. 


\section{TX-115}

Tank TX-115 was classified as a dormant leaker in 1972 and questionable integrity in 1984. The basis for the dormant leaker classification was increased activity in area dry wells (Occurrence Report 76-47). The tank was classified as Removed from Service in 1974 and later reclassified as Active in 1976.

Tank TX-115 is one of 19 tanks grouped together (see Table 5) to estimate a cumulative leak volume based on the assumption that their mean leak volume was approximately the same as the mean leak volume for 18 tanks which were considered to be "typical leakers". The 18 typical leakers were determined to have a mean estimated leak volume of 7,782 gal. After some rounding, this group of 19 tanks were assessed a cumulative leak volume estimate of 150,000 gal with individual leak volume estimates of 8,000 gal each [Jensen, 1989, Baumhardt, 1989, and Hanlon, 1999].

\section{TX-116}

Tank TX-116 was classified as questionable integrity in 1976. In 1972, 95 tons of diatomaceous earth were added in an attempt to stabilize the tank. More than 100,000 gal of liquid were salt well pumped before the tank was classified as interim-stabilized.

Tank TX-116 is one of 19 tanks grouped together (see Table 5) to estimate a cumulative leak volume based on the assumption that their mean leak volume was approximately the same as the mean leak volume for 18 tanks which were considered to be "typical leakers". The 18 typical leakers were determined to have a mean estimated leak volume of 7,782 gal. After some rounding, this group of 19 tanks were assessed a cumulative leak volume estimate of $150,000 \mathrm{gal}$ with individual leak volume estimates of 8,000 gal each [Jensen, 1989, Baumhardt, 1989, and Hanlon, 1999].

\section{TX-117}

Tank TX-117 was classified as questionable integrity in 1977. The tank was removed from service in 1969. In 1971 an unsuccessful attempt to stabilize the tank was made by adding 41 tons of diatomaceous earth. Photographs taken inside the tank in 1969 show a radial crack in the tank's concrete dome.

Tank TX-117 is one of 19 tanks grouped together (see Table 5) to estimate a cumulative leak volume based on the assumption that their mean leak volume was approximately the same as the mean leak volume for 18 tanks which were considered to be "typical leakers". The 18 typical leakers were determined to have a mean estimated leak volume of 7,782 gal. After some rounding, this group of 19 tanks were assessed a cumulative leak volume estimate of $150,000 \mathrm{gal}$ with individual leak volume estimates of 8,000 gal each [Jensen, 1989, Baumhardt, 1989, and Hanlon, 1999].

\section{TY Farm}

The TX Farm comprises six 100 series, dish bottom tanks built between 1951 and 1952 . These tanks are $75 \mathrm{ft}$ in diameter with a capacity of 758,000 gal. They were designed to store non-boiling wastes at temperatures up to $220^{\circ} \mathrm{F}$. The TY farm tanks were initially used to settle and decant low-level waste and as lag storage for feeding the 242-T evaporator. 


\section{TY-101}

Tank TY-101 was declared an assumed leaker and removed from service in 1973. The basis of this classification was an unexplained liquid level decrease of greater than 0.3 in.

This tank is one of 24 tanks for which the leak volume estimate is based solely on liquid level calculations. It is also one of the 18 "typical" tanks used to estimate leak volume for 19 other SSTs with assumed leaks that could not be estimated by surface level measurements. The estimated leak volume for TY-101 is less than 1,000 gal.

\section{TY-103}

Tank TY-103 was classified as a confirmed leaker in 1973 and inactive in 1976. Dry wells 52-03-06 and 52-03-03 had shown activity increase, indicating leakage from either TY-103 or TY-105. An Operating Limit Deviation Report (82-09) was issued in 1982 because of an unexplained liquid level decrease. The estimated leak volume for this tank is $3,000 \mathrm{gal}$.

\section{TY-104}

Tank TY-104 was classified as questionable integrity and removed from service in 1974 following an unexplained liquid level decrease of more than $0.3 \mathrm{in}$. It was reclassified as a confirmed leaker in 1981 based on recommendations made by a review team on the reclassification of five questionable integrity tanks.

This tank is one of 24 tanks for which the leak volume estimate is based solely on liquid level calculations. It is also one of the 18 "typical" tanks used to estimate leak volume for 19 other SSTs with assumed leaks that could not be estimated by surface level measurements. The estimated leak volume for tank TY-104 is 1,400 gal.

\section{TY-105}

Tank TY-105 was classified as a confirmed leaker in 1959 and removed from service in 1960. Both dry wells associated with this tank show activity. The estimated leak volume for this tank is $35,000 \mathrm{gal}$.

\section{TY-106}

Tank TY-106 was classified as a confirmed leaker and removed from service in 1959. In February 1972, 27 tons of diatomaceous earth were added in an attempt to stabilize the tank. Four of the five dry wells associated with this tank have shown activity. The estimated leak volume for this tank is 20,000 gal.

\section{U Farm}

The $U$ farm contains twelve 100 series and four 200 series dish bottom tanks built between 1943 and 1944. The 100 series tanks are $75 \mathrm{ft}$ in diameter with a capacity of 530,000 gal. The 200 series tanks are $20 \mathrm{ft}$ in diameter with a capacity of 54,000 gal. Tanks U-101 through U109 initially received waste from T Plant and were subsequently sluiced back to U Plant for the TBP recovery process. Tanks U-110 through U-112 initially received decontamination waste 


\section{U-101}

Tank U-101 was classified as a confirmed leaker and removed from service in 1959. From 1969 to 1972 the tank received a variety of solid wastes, including six casks of experimental fuel elements, shroud tubes, and ceramic samarium balls from May 1969 to June 1971. The estimated leak volume for this tank is 30,000 gal.

\section{U-104}

Tank U-104 was classified as a confirmed leaker and removed from service in 1961. It was interim-stabilized by the addition of diatomaceous earth. A ruptured tank bottom was detected in 1956 when the installation of a heel jet could not be accomplished [Roberts, 1961]. Occurrence Report 78-09 was written in 1978 because of increasing activity in dry well $60-04-08$. The estimated leak volume for this tank is 55,000 gal.

\section{U-110}

Tank U-110 was classified as a confirmed leaker and pumped to a minimum heel in 1975 . The basis for this action was increasing activity in dry well 60-10-07 that could not be explained by anything other than a tank leak. Waste transfers masked liquid level decreases that had been slowly accumulating over 14 months. The accumulated level drop over this period was approximately 3 in, which provides the basis for the estimated leak volume of $8,100 \mathrm{gal}$.

This tank is one of 24 tanks for which the leak volume estimate is based solely on liquid level calculations. It is also one of the 18 "typical" tanks used to estimate leak volume for 19 other SSTs with assumed leaks that could not be estimated by surface level measurements.

\section{U-112}

Tank U-112 was classified as questionable integrity and removed from service in 1970 . The basis for this action was an unexplained liquid level decrease. Moreover, large activity peaks were discovered in dry well 60-12-01 when it was drilled in 1974. In 1980 the tank was reclassified as a confirmed leaker based on the recommendations of a review team evaluating the reclassification of nine questionable integrity tanks.

This tank is one of 24 tanks for which the leak volume estimate is based solely on liquid level calculations. It is also one of the 18 "typical" tanks used to estimate leak volume for 19 other SSTs with assumed leaks that could not be estimated by surface level measurements. The estimated leak volume for tank $\mathrm{U}-112$ is 8,500 gal. 


\section{Leak Rate Analysis}

A detailed engineering study to estimate leak rates associated with hydraulic retrieval of sludge from tank C-106 was performed in 1993 (Lowe, 1993). This study estimated leak rates from a distribution of 20 stress corrosion cracks to be as high as 40,000 gal over a 500 hour retrieval campaign for an overall leak rate of $80 \mathrm{gal} / \mathrm{hr}$. No leaks have been detected to date during the Project W-320 sluicing operation for C-106.

An earlier study (Isaacson, 1981) identified 13 leaking SSTs with "confirmed" or "postulated" leak rates. After declaring three of these tanks as catastrophic leakers and removing them from the population, this study found that $95 \%$ of the SSTs would leak at a rate less than $1.8 \mathrm{gal} / \mathrm{hr}$ with $95 \%$ confidence.

Since the Isaacson, 1981 report, leak rates for four additional tanks have been determined either through direct historical reference or through calculation. In addition, leak rates for some Savannah River Site tanks are available through Savannah River Site historical references. Table 12 below tabulates available leak rate information for both Hanford and Savannah River tanks.

In 1998, a Historical Leak Model was developed by Los Alamos National Laboratory that utilized tank level and temperature data with recorded fill and transfer records to calculate the expected heat load in a tank and from there calculate the expected losses due to evaporation and perform a mass balance calculation to determine the amount of unaccounted for waste volume (i.e., leaks) [Agnew 1998]. The Historical Leak Model calculated significantly higher leak volumes for tanks SX-105, SX-108, SX-109, SX-111, and SX-112. A subsequent review of the Hanford Leak Model found that the precision of the model inputs lacked the precision and accuracy required to estimate the tank leak volumes [Jones, 1999]. 
Table 12. Leak Rates for some Hanford and Savannah River SSTs

\begin{tabular}{ccl}
\hline Tank & Leak Rate (gph) & \multicolumn{1}{c}{ Reference } \\
\hline SX-115 & 306 & Referenced in Isaacson, 1981 - "Confirmed" \\
T-106 & 102 & Referenced in Isaacson, 1981 - "Confirmed" \\
B-201 & 0.30 & Referenced in Isaacson, 1981 - "Confirmed" \\
B-107 & 0.66 & Referenced in Isaacson, 1981 - "Confirmed" \\
C-101 & 1.14 & Referenced in Isaacson, 1981 - "Confirmed" \\
U-112 & 1.20 & Referenced in Isaacson, 1981 - "Confirmed" \\
U-110 & 1.38 & Referenced in Isaacson, 1981 - "Confirmed" \\
T-108 & 0.09 & Referenced in Isaacson, 1981 - "Postulated" \\
T-111 & 0.12 & Referenced in Isaacson, 1981 - "Postulated" \\
TX-107 & 0.36 & Referenced in Isaacson, 1981 - "Postulated" \\
TY-101 & 0.78 & Referenced in Isaacson, 1981 - "Postulated" \\
B-110 & 1.20 & Referenced in Isaacson, 1981 - "Postulated" \\
SX-110 & 12.00 & Referenced in Isaacson, 1981 - "Postulated" \\
SX-113 & 55 & Referenced in GE Report, HW-75714 \\
A-105 & 0.3 to 6 & Caiculated from Leak Basis Narrative \\
U-104 & 140 & Calculated from 1961 GE Memo \\
BX-102 & 1 & Calculated from Womack, 1971 \\
SRS Tank 9 & $\sim 3$ & Referenced in duPont Report DP-1358 \\
SRS Tank 10 & $\sim 3$ & Referenced in duPont Report DP-1358 \\
SRS Tank 14 & $\sim 3$ & Referenced in duPont Report DP-1358 \\
SRS Tank 16 & 240 & Referenced in duPont Report DP-1358 \\
\hline & &
\end{tabular}




\section{Conclusions and Recommendations}

This report demonstrates that available information for SST leak history is highly variable in its level of detail. Several tanks have had extensive, detailed evaluations of their histories already prepared. Many other tanks have little historical information readily available. An accurate determination of leak dates and leak rates has been problematic. This information is important to the determination of the volume of the leaks and the composition of the wastes leaked.

Since the SSTs were taken out of service, a number of circumstances regarding SST retrieval have changed. First, some of the SSTs have been "interim-stabilized"; that is, pumpable liquids have been removed, leaving sludge and salt cake in a stable condition while they await retrieval). Second, there has been some degradation of tank liners. Third, the "leak designation" of some SSTs has changed (i.e., whether they are considered leaking or not). And fourth, there have been changes in retrieval technology. All of these circumstances must be considered in context in order to devise a viable retrieval strategyone that allows efficient waste retrieval and at the same time minimizes the risk of leaks into the vadose zone. As the condition of the tanks continues to degrade, retrieval options may become limited to technologies that would not cause further degradation.

The following recommendations are submitted for consideration in future SST integrity and retrieval assessments:

1. A detailed, focused review of the history of a specific SST should be conducted prior to any retrieval technique decision for that tank. The review should focus on the identification of any disqualifiers for the use of a specific retrieval technique. The assessment provided in this report provides an overview of the available leak history information and a bibliographic starting point for future detailed assessments.

2. The waste grouping information developed by Anantatmula in 1994 should be updated in light of the more recently prepared Hanford Defined Waste Model. 


\section{$8 \quad$ References}

Agnew, S. F., 1998, "Analysis of SX Farm Leak Histories - Historical Leak Model," HNF-3233, Rev. 0, Los Alamos National Laboratory, Los Alamos, New Mexico.

Anantatmula, R. P., 1994, "Characterization of the Corrosion Behavior of the Carbon Steel Liner in Hanford Single-Shell Tanks," WHC-EP-0772, Rev. 0, Westinghouse Hanford Company, Richland, Washington.

Anderson, J. D., 1990, "A History of the 200 Area Tank Farms," WHC-MR-0182, Westinghouse Hanford Company, Richland, Washington.

Baumhardt, R.J., May 15, 1989, Letter to R.E. Gerton, U.S. Department of EnergyRichland Operations Office, "Single Shell Tank Leak Volumes," 8901832B R1, Westinghouse Hanford Company, Richland, Washington.

Brevick, C. H., 1993, "Hanford Site Single-Shell Tank Level Histories for Corrosion Analysis," WHC-SD-WM-ER-209, Rev. 0, Kaiser Engineers Hanford Company, Richland, Washington.

Brevick, C. H., 1994, "Historical Tank Content Estimate for the Northeast Quadrant of the Hanford 200 East Area," WHC-SD-WM-ER-349, Rev. 0, Westinghouse Hanford Company, Richland, Washington.

Burton, G., April 1, 1974, Letter to G. T. Stocking, “108-BX Tank Leak," Atlantic Richfield Hanford Company, Richland, Washington.

DeFigh-Price, C., 1980, "Status of Tank Assessment Studies for Continued In-Tank Storage of Hanford High-Level Defense Waste," RHO-LD-142, Rockwell Hanford Operations, Richland, Washington.

DeFigh-Price, C., 1981, "Waste Tank 241-SX-115 Core Drilling Results," RHO-CD-1538, Rockwell Hanford Operations, Richland, Washington.

Edgemon, G. L., 1995, "Hanford Waste Tank System Degradation Mechanisms," WHCSD-WM-ER-414, Rev. 1, Westinghouse Hanford Company, Richland, Washington.

Eppel, T., 1998, "Tank Leak Assessment Process: Technical Background," HNF-3747, Rev. 0, Lockheed Martin Hanford Corporation, Richland, Washington.

Girdler, R. M., 1965, “Leaks in Radioactive Waste Tanks,” DP-990, E. I. du Pont de Nemours \& Company, Aiken, South Carolina.

Hanlon, B. M., 1999, "Waste Tank Summary Report for Month Ending January 31, 1999," (Published April 1999), HNF-EP-0182-130, Fluor Daniel Hanford, Inc., Richland, Washington. 
Hanson, G. L., 1962, "Leak Testing of the 113-SX Tank, HW-75714, General Electric Hanford Atomic Products Operation, Richland, Washington.

Hendrickson, D. W., 1997, “AX Tanks Farms Waste Inventory Study for the Hanford Tanks Initiative Project, HNF-SD-HTI-TI-001, Rev 0A (formerly identified as SESC-EN-RPT-002, Rev. 1), SGN Eurisys Services Corporation, Richland, Washington.

Hill, J. G., 1994, "SORT on Radioactive Waste Tanks at Hanford," WHC-PNL-90814, Rev. 2, Westinghouse Hanford Company, Richland, Washington.

Jensen, L, 1989, "Estimation of Single-Shell Tank Leak Volumes," Internal Correspondence No. 12710-89-042, to R. E. Raymond, Westinghouse Hanford Company, Richland, Washington, March 28, 1989.

Jones, T. E., 1999, "Assessment of Historical Leak Model Methodology as Applied to the REDOX High-Level Waste Tank SX-108," HNF-4756, Rev. 0, Lockheed Martin Hanford Corporation, Richland, Washington, September 1999.

Isaacson, R. E., 1981, "A Scientific Basis for Establishing Dry Well-Monitoring Frequencies," RHO-ST-34-201, Rockwell Hanford Operations, Richland, Washington.

Isaacson, R. E., 1982, "Supporting Information for the Scientific Basis for Establishing Dry Well-Monitoring Frequencies," RHO-RE-EV-4 P-201, Rockwell Hanford Operations, Richland, Washington.

Lowe, S. S., 1993, "Engineering Study of Tank Leaks Related to Retrieval of Sludge from Tank 241-C-106," WHC-SD-WM-ES-218, Rev. 0, Westinghouse Hanford Company, Richland, Washington, June 1993.

Neilsen, E. H., 1991, “Tank 241-A-105 Leak Assessment,” WHC-MR-0264, Westinghouse Hanford Company, Richland, Washington.

Neilsen, E. H., 1992a, “Tank 241-SX-109 Leak Assessment,” WHC-MR-0301, Westinghouse Hanford Company, Richland, Washington.

Neilsen, E. H., 1992b, "Tank 241-SX-108 Leak Assessment," WHC-MR-0300, Westinghouse Hanford Company, Richland, Washington.

Neilsen, E. H., 1992c, "Tank 241-SX-115 Leak Assessment," WHC-MR-0302, Westinghouse Hanford Company, Richland, Washington.

Ondrejcin, R. S., 1978, "Prediction of Stress Corrosion of Carbon Steel by Nuclear Process Liquid Wastes," DP-1478, E. I. du Pont de Nemours \& Co., Aiken, South Carolina, 1978. 
Poe, W.L., 1974, "Leakage from Waste Tank 16 - Amount, Fate, and Impact," DP-1358, E. I. du Pont de Nemours \& Company, Aiken, South Carolina.

Rasmussen, O. R., 1980, "Hanford Radioactive Tank Cleanout and Sludge Processing," RHO-ST-30, Rev. 0, Rockwell Hanford Operations, Richland, Washington, March 1980.

Roberts, R. E., 1961 (Recipient from unknown author), "History of the 104-U Tank," Internal Correspondence, General Electric Corporation, Richland, Washington, February 9, 1961.

Rodenhizer, D. G., 1987, "Hanford Waste Tank Sluicing History," WHC-SD-WM-TI-302, Rev. 0, Westinghouse Hanford Company, Richland, Washington, September 1987.

Sindelar, R.L., et al, 1995, "SRS High Level Waste Tank and Piping Systems - Structural Integrity Program and Topical Report, WSRC-TR-95-0076, Rev. 0, Westinghouse Savannah River Company, Aiken, South Carolina.

Smith, A. E., 1973, "241-T-106 Tank Leak Investigation," ARH-2874, Atlantic Richfield Hanford Company, Richland, Washington.

"Tank Leak Assessment Process," 1999, HNF-SD-WM-PROC-021, Section 26.1, Rev. 2, Lockheed Martin Hanford Corporation, Richland, Washington.

Thompson, R., 1999, “Leak Assessment Report for B-111," HNF-3652, Rev. 0, Lockheed Martin Hanford Corporation, Richland, Washington.

Vollert, F. R., 1979, "Structural Evaluations of Existing Reinforced Concrete Tanks for Radioactive Waste Storage," RHO-SA-108, Rockwell Hanford Operations, Richland, Washington.

Welty, R. K., 1988, "Waste Storage Tank Status and Leak Detection Criteria," WHC-SDWM-TI-356, Westinghouse Hanford Company, Richland, Washington.

WHC, 1992, Occurrence Report, "Apparent Decrease in Liquid Level in single Shell Underground Storage Tank 241-T-101, Leak suspected Investigation Continuing," RL-WHC-TANKFARM-1992-0073, Westinghouse Hanford Company, Richland, Washington.

Womack, J. C., 1971, "Investigation and Evaluation of 102-BX Tank Leak," ARH-2035, Atlantic Richfield Hanford Company, Richland, Washington. 
This page intentionally left blank 


\section{Appendix A}

\section{Tank Specific Data Tables}




\begin{tabular}{|c|c|c|c|c|c|c|c|c|c|c|c|c|}
\hline Tank & $\frac{\dot{0}}{3}$ & 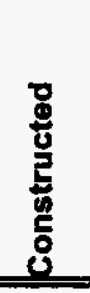 & $\begin{array}{l}\frac{8}{2} \\
\text { ह } \\
\end{array}$ & 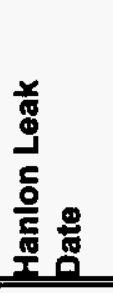 & 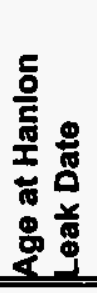 & 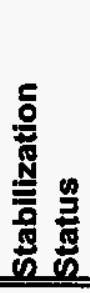 & 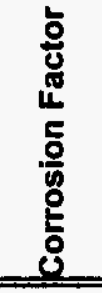 & 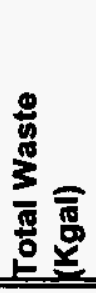 & 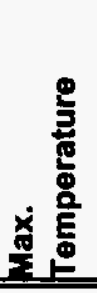 & $\begin{array}{l}\frac{0}{y} \\
\frac{0}{3} \\
\frac{5}{2} \\
\frac{1}{5} \\
\vdots \\
\end{array}$ & 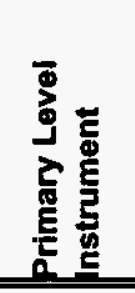 & 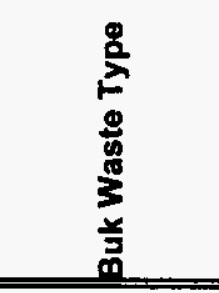 \\
\hline$A-103(T)$ & $4 / 1 M$ & 1955 & 1956 & 1987 & 32 & $|S /| \mid$ & 0.77 & 371 & & Radius & ENRAF & DSSF, NCPLX \\
\hline $\mathrm{A}-104(\mathrm{~T})$ & $4 / 1 M$ & 1955 & 1957 & 1975 & 20 & $|S /| \mid$ & 0 & 28 & 187 & Radius & No Data & DSSF, NCPLX \\
\hline A-105 & $4 / 1 M$ & 1955 & 1957 & 1963 & 8 & IS/II & 0 & 19 & 141 & Radius & No Data & DSSF, NCPLX \\
\hline$A X-102(T, H)$ & $4 / 1 M$ & 1964 & 1966 & 1988 & 24 & IS/II & 1.1 & 39 & 78 & Butt-weld & No Data & Ungrouped \\
\hline$A X-104(T)$ & $4 / 1 \mathrm{M}$ & 1964 & 1966 & 1977 & 13 & IS/II & 0 & 7 & & Butt-weld & No Data & Ungrouped \\
\hline B-101 (T) & $2 / 530 \mathrm{~K}$ & 1943 & 1945 & 1974 & 31 & IS/II & 9.12 & 113 & & Radius & No Data & Ungrouped \\
\hline B-103 (T) & $2 / 530 \mathrm{~K}$ & 1943 & 1946 & 1978 & 35 & IS/II & 9.12 & 59 & 66 & Radius & No Data & DSSF, NCPLX \\
\hline B-105 & $2 / 530 \mathrm{~K}$ & 1943 & 1947 & 1978 & 35 & IS/II & 22.02 & 306 & & Radius & LOW & CCPLX, DSSF \\
\hline B-107 & $2 / 530 \mathrm{~K}$ & 1943 & 1945 & 1980 & 37 & IS/II & 11.01 & 165 & & Radius & No Data & CCPLX, DSSF \\
\hline $\mathrm{B}-110(\mathrm{~T})$ & $2 / 530 \mathrm{~K}$ & 1943 & 1945 & 1981 & 38 & $|\mathbf{S} /| \mid$ & 5 & 246 & & Radius & LOW & Ungrouped \\
\hline B-111 & $2 / 530 \mathrm{~K}$ & 1943 & 1946 & 1978 & 35 & IS/II & 5 & 237 & & Radius & LOW & $\mathrm{CW}, \mathrm{EB}$ \\
\hline $\mathrm{B}-112(\mathrm{~T})$ & $2 / 530 \mathrm{~K}$ & 1943 & 1946 & 1978 & 35 & $|S /| \mid$ & 5 & 33 & & Radius & ENRAF & CW, EB \\
\hline B-201 & $1 / 55 K$ & 1943 & 1952 & 1980 & 37 & IS/II & 1.8 & 29 & & Radius & No Data & CW, EB \\
\hline B-203 & $1 / 55 \mathrm{~K}$ & 1943 & 1952 & 1983 & 40 & IS/II & 1.8 & 51 & & Radius & No Data & Ungrouped \\
\hline B-204 & $1 / 55 \mathrm{~K}$ & 1943 & 1952 & 1984 & 41 & IS/II & 1.8 & 50 & & Radius & No Data & $E B, 1 C$ \\
\hline$B X-101(T)$ & $2 / 530 \mathrm{~K}$ & 1947 & 1948 & 1972 & 25 & $|\mathbf{I S} /|$ & 57.18 & 43 & & Radius & No Data & 1C, TBP \\
\hline $\mathrm{BX}-102(\mathrm{~T})$ & $2 / 530 \mathrm{~K}$ & 1947 & 1948 & 1971 & 24 & IS/II & 57.18 & 96 & & Radius & No Data & 1C, EB \\
\hline$B X-108$ & 2/530K & 1947 & 1949 & 1974 & 27 & IS/II & 26.43 & 26 & & Radius & No Data & 1C, EB \\
\hline$B X-110$ & $2 / 530 \mathrm{~K}$ & 1947 & 1950 & 1976 & 29 & IS/PI & 12.43 & 207 & & Radius & ENRAF & 1C, EB \\
\hline$B X-111$ & $2 / 530 \mathrm{~K}$ & 1947 & 1950 & 1984 & 37 & IPI & 12.43 & 162 & & Radius & No Data & $2 C, 5-6$ \\
\hline $\mathrm{BY}-103(\mathrm{~T}, \mathrm{Fe})$ & $3 / 750 \mathrm{~K}$ & 1949 & 1951 & 1973 & 24 & $/ \mathrm{PI}$ & 45.5 & 400 & 81 & Radius & LOW & $2 C, 5-6$ \\
\hline BY-105 (T, Fe) & $3 / 750 \mathrm{~K}$ & 1949 & 1951 & 1984 & 35 & IPI & 45.5 & 503 & 118 & Radius & LOW & $2 C, 5-6$ \\
\hline BY-106 & $3 / 750 \mathrm{~K}$ & 1949 & 1953 & 1984 & 35 & $/ \mathrm{PI}$ & 45.5 & 642 & 122 & Radius & LOW & 224 \\
\hline BY-107 (Fe) & $3 / 750 \mathrm{~K}$ & 1949 & 1951 & 1984 & 35 & IS/II & 45.5 & 266 & 95 & Radius & LOW & 224 \\
\hline BY-108 $(\mathrm{Fe})$ & $3 / 750 \mathrm{~K}$ & 1949 & 1951 & 1972 & 23 & IS/II & 45.5 & 228 & 108 & Radius & No Data & 224 \\
\hline C-101 (T) & 2/530K & 1944 & 1946 & 1980 & 36 & $|S / I|$ & 57.18 & 88 & & Radius & No Data & 224 \\
\hline $\mathrm{C}-110(\mathrm{~T})$ & $2 / 530 \mathrm{~K}$ & 1944 & 1946 & 1984 & 40 & $\mid \mathrm{PI}$ & 26.43 & 187 & & Radius & No Data & TBP, CW \\
\hline $\mathrm{C}-111(\mathrm{~T})$ & 2/530K & 1944 & 1947 & 1968 & 24 & IS/II & 35.83 & 57 & 77 & Radius & No Data & TBP, CW \\
\hline C-201 & $1 / 55 \mathrm{~K}$ & 1944 & 1948 & 1988 & 44 & IS/II & 1.59 & 2 & & Radius & No Data & TBP, CW \\
\hline C-202 & $1 / 55 \mathrm{~K}$ & 1944 & 1948 & 1988 & 44 & IS/II & 1.59 & 1 & & Radius & No Data & TBP, CW \\
\hline C-203 & $1 / 55 \mathrm{~K}$ & 1944 & 1948 & 1984 & 40 & $|S / I|$ & 1.59 & 5 & & Radius & No Data & TBP, CW \\
\hline C-204 & $1 / 55 \mathrm{~K}$ & 1944 & 1948 & 1988 & 44 & $|\mathbf{S} /| \mid$ & 1.59 & 3 & & Radius & No Data & TBP, CW \\
\hline$S-104(T)$ & $3 / 750 \mathrm{~K}$ & 1951 & 1952 & 1968 & 17 & IS/II & 6.53 & 294 & & Radius & LOW & 1C, TBP \\
\hline$S X-104(T)$ & $4 / 1 \mathrm{M}$ & 1954 & 1955 & 1988 & 34 & IPI & 13.66 & 614 & 166 & Butt-weld & LOW & 1C, TBP \\
\hline $\mathrm{SX}-107(\mathrm{~T})$ & $4 / 1 \mathrm{M}$ & 1954 & 1956 & 1964 & 10 & IS/II & 6.53 & 104 & 170 & Butt-weld & No Data & Ungrouped \\
\hline$S X-108(T)$ & $4 / 1 M$ & 1954 & 1955 & 1962 & 8 & IS/II & 6.53 & 87 & 197 & Butt-weld & No Data & 1C, EB-ITS \\
\hline$s \times-109(T)$ & $4 / 1 \mathrm{M}$ & 1954 & 1956 & 1965 & 11 & IS/II & 6.53 & 250 & 151 & Butt-weld & No Data & 1C, EB-ITS \\
\hline$S X-110(T)$ & $4 / 1 \mathrm{M}$ & 1954 & 1960 & 1976 & 22 & IS/II & 6.07 & 62 & 170 & Butt-weld & No Data & $1 C, E B$ \\
\hline$S X-111(T)$ & $4 / 1 M$ & 1954 & 1957 & 1974 & 20 & IS/II & 6.07 & 125 & 194 & Butt-weld & No Data & TBP-F, EB-ITS \\
\hline$S X-112(T)$ & $4 / 1 \mathrm{M}$ & 1954 & 1956 & 1969 & 15 & $|S / I|$ & 6.53 & 92 & 155 & Butt-weld & No Data & TBP, EB-ITS \\
\hline$S X-113(T)$ & $4 / 1 \mathrm{M}$ & 1954 & 1958 & 1962 & 8 & $|\mathbf{S} /| \mid$ & 4.57 & 26 & & Butt-weld & No Data & TBP-F, EB-ITS \\
\hline
\end{tabular}




\begin{tabular}{|c|c|c|c|c|c|c|c|c|c|c|c|c|}
\hline Tank & 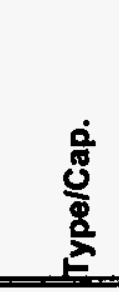 & 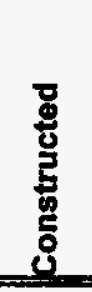 & $\begin{array}{l}8 \\
\frac{8}{2} \\
8 \\
0 \\
\end{array}$ & 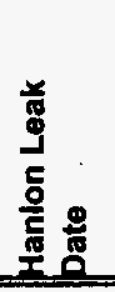 & 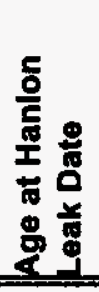 & 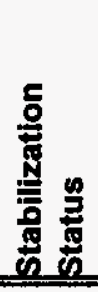 & 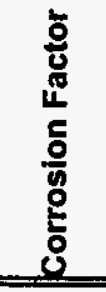 & 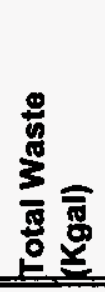 & 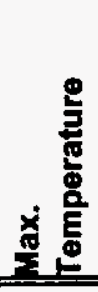 & 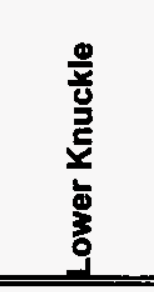 & 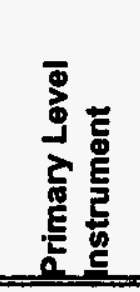 & 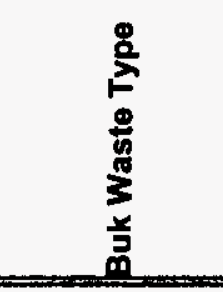 \\
\hline$S X-114(T)$ & $4 / 1 \mathrm{M}$ & 1954 & 1957 & 1972 & 18 & $|S /| \mid$ & 6.07 & 181 & 188 & Butt-weld & No Data & TBP-F, EB-ITS \\
\hline$S X-115(T)$ & $4 / 1 \mathrm{M}$ & 1954 & 1959 & 1965 & 11 & IS/II & 6.53 & 12 & & Butt-weld & No Data & TBP-F, EB-ITS \\
\hline$T-101(T)$ & $2 / 530 \mathrm{~K}$ & 1944 & 1945 & 1992 & 48 & IS/PI & 0.1 & 102 & & Radius & No Data & TBP-F, EB-ITS \\
\hline T-103 & $2 / 530 \mathrm{~K}$ & 1944 & 1946 & 1974 & 30 & IS/II & 0.1 & 27 & & Radius & No Data & TBP-F, EB-ITS \\
\hline$T-106(7$ & $2 / 530 \mathrm{~K}$ & 1944 & 1947 & 1973 & 29 & $|S /| \mid$ & 1.94 & 21 & & Radius & No Data & TBP-F, EB-ITS \\
\hline T-107 & $2 / 530 \mathrm{~K}$ & 1944 & 1945 & 1984 & 40 & IPI & 35.83 & 180 & 70 & Radius & No Data & TBP, EB-ITS \\
\hline$T-108$ & $2 / 530 \mathrm{~K}$ & 1944 & 1946 & 1974 & 30 & $\mid \mathrm{S} / \mathrm{I}$ & 26.43 & 44 & & Radius & No Data & TBP-F, EB-ITS \\
\hline$T-109$ & $2 / 530 \mathrm{~K}$ & 1944 & 1946 & 1974 & 30 & $\mid S / \|$ & 0 & 58 & & Radius & No Data & TBP-F, EB-ITS \\
\hline T-111 & $2 / 530 \mathrm{~K}$ & 1944 & 1946 & 1979 & 35 & $/ \mathrm{PI}$ & 4.04 & 446 & 67 & Radius & LOW & TBP-F, EB-ITS \\
\hline$T X-105(C$ & $3 / 750 \mathrm{~K}$ & 1948 & 1952 & 1977 & 29 & IS/II & 13.66 & 609 & 99 & Radius & No Data & TBP, CW \\
\hline TX-107 & $3 / 750 \mathrm{~K}$ & 1948 & 1952 & 1984 & 36 & IS/II & 13.66 & 36 & & Radius & No Data & CW, TBP \\
\hline TX-110 & $3 / 750 \mathrm{~K}$ & 1948 & 1950 & 1977 & 29 & $|S / I|$ & 22.02 & 462 & & Radius & LOW & SS, TBP \\
\hline TX-113 & $3 / 750 \mathrm{~K}$ & 1948 & 1952 & 1974 & 26 & $|S /| \mid$ & 22.02 & 607 & & Radius & LOW & Ungrouped \\
\hline TX-114 & $3 / 750 \mathrm{~K}$ & 1948 & 1952 & 1974 & 26 & IS/II & 22.02 & 535 & & Radius & LOW & CW, TBP \\
\hline TX-115 & $3 / 750 \mathrm{~K}$ & 1948 & 1952 & 1977 & 29 & $|S /| \mid$ & 23.16 & 640 & & Radius & LOW & SS, TBP \\
\hline TX-116 & $3 / 750 \mathrm{~K}$ & 1948 & 1952 & 1977 & 29 & $|S /| \mid$ & 22.02 & 631 & & Radius & No Data & Ungrouped \\
\hline TX-117 & $3 / 750 \mathrm{~K}$ & 1948 & 1952 & 1977 & 29 & IS/II & 22.02 & 626 & & Radius & LOW & TBP-F, $1 \mathrm{C}$ \\
\hline TY-101 (T) & $3 / 750 \mathrm{~K}$ & 1952 & 1954 & 1973 & 21 & IS/II & 0 & 118 & 65 & Radius & No Data & TBP-F, $1 C$ \\
\hline$T Y-103(T)$ & $3 / 750 \mathrm{~K}$ & 1952 & 1954 & 1973 & 21 & IS/II & 57.99 & 162 & 70 & Radius & LoW & 1C, TBP \\
\hline$T Y-104(0)$ & $3 / 750 \mathrm{~K}$ & 1952 & 1954 & 1981 & 29 & $|S /|$ & 57.99 & 46 & 71 & Radius & ENRAF & TBP-F, 1C \\
\hline TY-105 & $3 / 750 \mathrm{~K}$ & 1952 & 1953 & 1960 & 8 & $|S /| \mid$ & 81.67 & 231 & & Radius & No Data & TBP-F, 1C \\
\hline$T Y-106$ & $3 / 750 \mathrm{~K}$ & 1952 & 1954 & 1959 & 7 & IS/II & 81.67 & 17 & & Radius & No Data & HS \\
\hline$U-101$ & $2 / 530 \mathrm{~K}$ & 1944 & 1946 & 1959 & 15 & $\mid S / \|$ & 6.53 & 25 & & Radius & ENRAF & HS \\
\hline U-104 & $2 / 530 \mathrm{~K}$ & 1944 & 1948 & 1961 & 17 & IS/II & 4.57 & 122 & & Radius & No Data & HS \\
\hline$U-110(T$ & $2 / 530 \mathrm{~K}$ & 1944 & 1947 & 1975 & 31 & IS/PI & 0 & 186 & & Radius & No Data & HS \\
\hline$U-112$ & $2 / 530 \mathrm{~K}$ & 1944 & 1948 & 1980 & 36 & $\mid \mathrm{IS} / \mathrm{I}$ & 0 & 49 & & Radius & No Data & Redox, EB \\
\hline
\end{tabular}




\begin{tabular}{|c|c|c|c|c|c|c|}
\hline Tank & 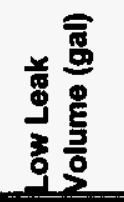 & 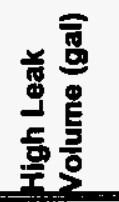 & 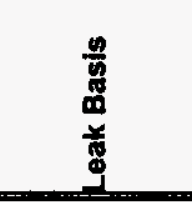 & 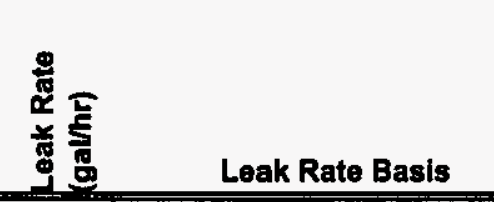 & Fallure Mode & 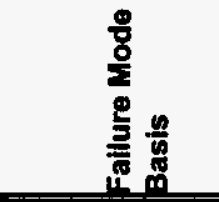 \\
\hline$A-103(T)$ & 5,500 & & level/dry well & & Bulge? & Suspect \\
\hline A-104 (T) & 500 & 2,500 & lateral & 1.3 Calc. - ARHCO 1975 Internal & Crack during sluicing & ARHCO Internal \\
\hline A-105 & 10,000 & 277,000 & level/ateral & 0.3 to 6 Calc - WHC-SD-WM-TI-356 & Thermal rupture & RHO-R-39 \\
\hline$A X-102(T, H)$ & 3,000 & & level/dry well & & 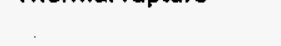 & \\
\hline$A X-104(T)$ & 8,000 & & dry weil & & & \\
\hline $\mathrm{B}-101(\mathrm{~T})$ & 8,000 & & dry well & & & \\
\hline $\mathrm{B}-103(\mathrm{~T})$ & 8,000 & & dry well & & & \\
\hline B-105 & 8,000 & & dry well & & & \\
\hline B-107 & 8,000 & & level & 0.67 Calc. RHO-RE-EV-4 P & & \\
\hline$B-110(T)$ & 10,000 & & level & 1.2 Calc. RHO-RE-EV-4 P & & \\
\hline B-111 & 8,000 & & dry well & & & \\
\hline $\mathrm{B}-112(\mathrm{~T})$ & 2,000 & & dry well & & & \\
\hline B-201 & 1,200 & & level/dry well & 0.03 Calc. RHO-RE-EV-4 P & & \\
\hline $\mathrm{B}-203$ & 300 & & level & 0.66 Confirmed - RHO-ST-34 & & \\
\hline B-204 & 400 & & level & & & \\
\hline$B X-101(T)$ & 8,000 & & dry well & & & \\
\hline$B X-102(T)$ & 70,000 & & dry well & 8 Calc-WHC-SD-WM-T1-356 & Pitting & ARH-2035 \\
\hline$B X-108$ & 2,500 & & level/dry well & 0.38 Calc. - 1974 ARHCO memo & & \\
\hline$B X-110$ & 8,000 & & dry well & & & \\
\hline$B X-111$ & 8,000 & & dry well/level & & & \\
\hline$B Y-103(T, F e)$ & 5,000 & & dry well & & & \\
\hline $\mathrm{BY}-105(\mathrm{~T}, \mathrm{Fe})$ & 8,000 & & dry weil & & & \\
\hline BY-106 & 8,000 & & dry welf & & & \\
\hline $\mathrm{BY}-107(\mathrm{Fe})$ & 15,100 & & level & & & \\
\hline $\mathrm{BY}-108(\mathrm{Fe})$ & 5,000 & & dry well & & & \\
\hline$C-101(T)$ & 20,000 & & level/dry well & 1.14 Caic. RHO-RE-EV-4 P & & \\
\hline $\mathrm{C}-110(\mathrm{~T})$ & 2,000 & & dry well & & & \\
\hline C.111(T) & 5,500 & & lovel & & & \\
\hline C-201 & 550 & & level? & & & \\
\hline $\mathrm{C}-202$ & 450 & & level? & & & \\
\hline C-203 & 400 & & level & & & \\
\hline C-204 & 350 & & level? & & & \\
\hline $\mathrm{S}-104(\mathrm{~T})$ & 24,000 & & level & & Bulge? & RHO-R-39 \\
\hline$S X-104(T)$ & 6,000 & & level & & Bulge? & RHO-R-39 \\
\hline SX-107 (T) & 5,000 & & & & Bulge & RHO-R-39 \\
\hline$S X-108(T)$ & 2,400 & 35,000 & lateral & & Bulge & RHO-R-39 \\
\hline$S X-109(T)$ & 10,000 & & lateral/dry well & & Bulge? & RHO-R-39 \\
\hline$S X-110(T)$ & 5,500 & & level & 12 Calc. RHO-RE-EV-4 P & Bulge? & RHO-R-39 \\
\hline$S X-111(T)$ & 500 & 2,000 & lateral & & Bulge? & RHO-R-39 \\
\hline$S X-112(T)$ & 30,000 & & & & Bulge & RHO-R-39 \\
\hline$S X-113(T)$ & 15,000 & & level/ateral & 55 GE Report HW-75714, 1962 & Bulge & RHO-R-39 \\
\hline$S X-114(T)$ & 8,000 & & dry well & & Bulge? & RHO-R-39 \\
\hline$S X-115(T)$ & 50,000 & & level & 306 Confirmed - RHO-ST-34 & Bulge? & \\
\hline$T-101(T)$ & 7,500 & & level & & & \\
\hline $\mathrm{T}-103$ & 1,000 & & lovel & 0.36 Calc. RHO-RE-EV-4 P & & \\
\hline$T-106(T)$ & 115,000 & & leveldry well & 102 Calc. RHO-RE-EV-4 P & & \\
\hline$T-107$ & 8,000 & & dry weli & & & \\
\hline
\end{tabular}




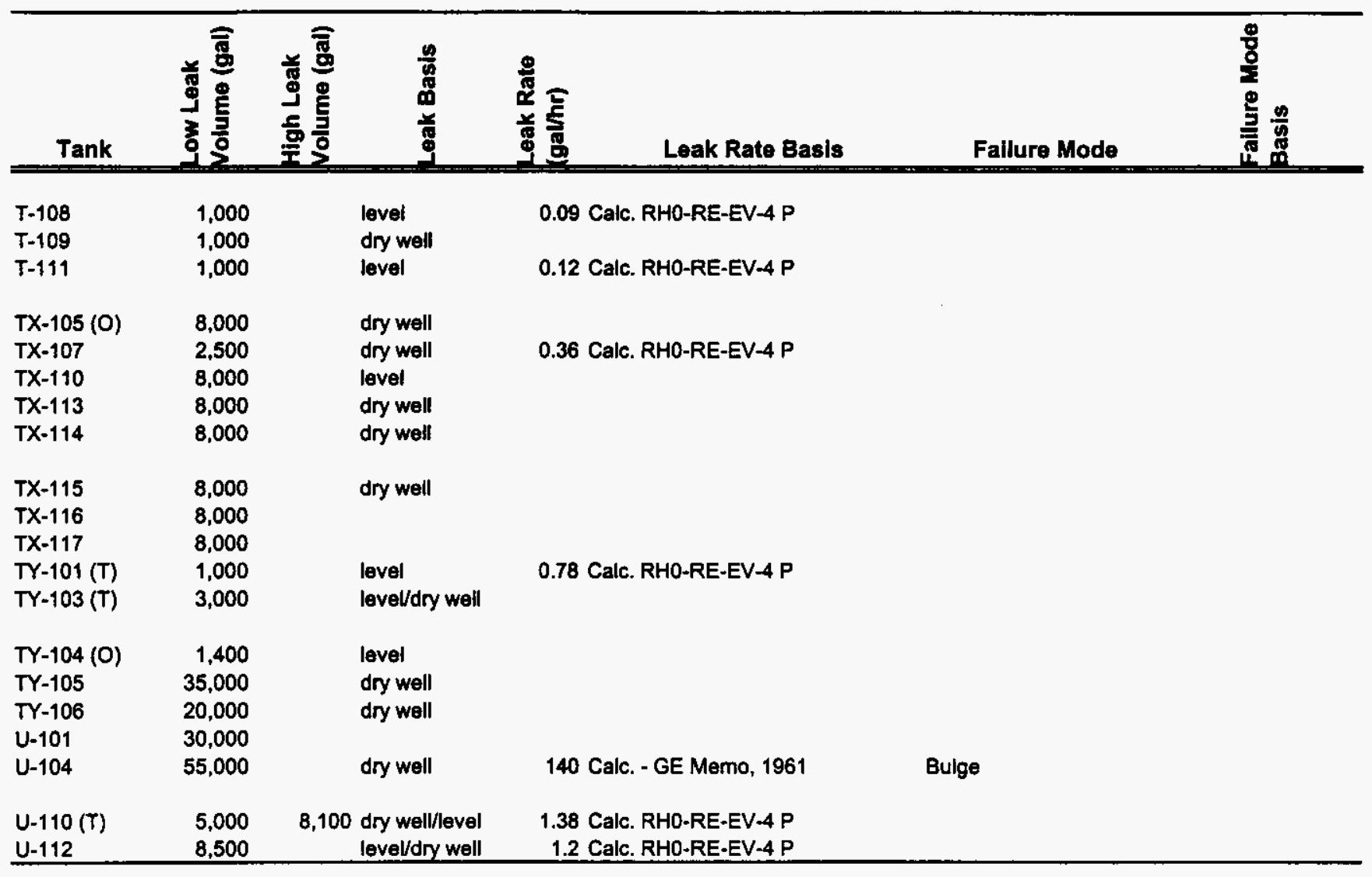




\begin{tabular}{|c|c|c|c|c|c|c|c|c|c|c|c|}
\hline Tank & 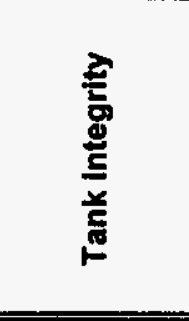 & 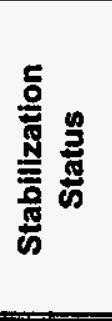 & 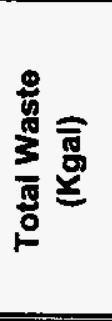 & 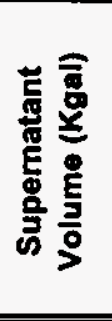 & 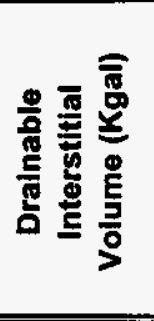 & 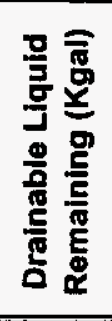 & 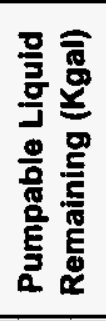 & 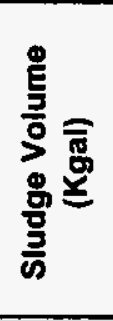 & 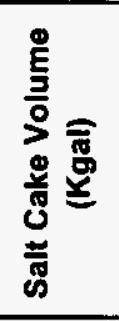 & 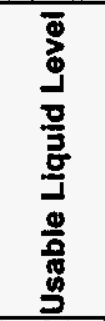 & 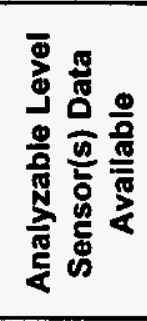 \\
\hline$A-101$ & SOUND & $|\mathbb{P}|$ & 953 & 0 & 464 & 464 & 441 & 3 & 950 & YES & ILL \\
\hline $\begin{array}{l}A-102 \\
A-103\end{array}$ & $\begin{array}{l}\text { SOUND } \\
\text { ASMD LKR }\end{array}$ & $\begin{array}{l}|S / P| \\
|S / I|\end{array}$ & $\begin{array}{c}41 \\
371\end{array}$ & $\begin{array}{l}4 \\
5\end{array}$ & $\begin{array}{c}2 \\
15\end{array}$ & $\begin{array}{c}6 \\
20\end{array}$ & $\begin{array}{l}0 \\
0\end{array}$ & $\begin{array}{c}15 \\
366\end{array}$ & $\begin{array}{c}22 \\
0\end{array}$ & $\begin{array}{l}\text { NO } \\
\text { YES }\end{array}$ & $\begin{array}{l}\text { NONE }^{2} \\
\text { ENRAF }\end{array}$ \\
\hline A-104 & ASMD LKR & $|S /| \mid$ & 28 & 0 & 0 & 0 & 0 & 28 & 0 & NO & $\mathrm{NONE}^{3,4}$ \\
\hline A-105 & ASMD LKR & IS/II & 19 & 0 & 4 & 4 & 0 & 19 & 0 & NO & $\mathrm{NONE}^{3}$ \\
\hline A-106 & SOUND & IS/II & 125 & 0 & 7 & 7 & 0 & 125 & 0 & YES & $N^{\prime} N^{2}$ \\
\hline$A X-101$ & SOUND & $/ \mathrm{PI}$ & 748 & 0 & 359 & 359 & 338 & 3 & 745 & YES & $N_{O N E^{2}}$ \\
\hline$A X-102$ & ASMD LKR & IS/II & 39 & 3 & 14 & 17 & 3 & 7 & 29 & YES & $\mathrm{MT}^{\overline{7}}$ \\
\hline $\begin{array}{l}A X-103 \\
A X-104\end{array}$ & $\begin{array}{l}\text { SOUND } \\
\text { ASMD LKR }\end{array}$ & $\begin{array}{l}\text { IS/II } \\
\text { IS/II }\end{array}$ & $\begin{array}{c}112 \\
7\end{array}$ & $\begin{array}{l}0 \\
0\end{array}$ & $\begin{array}{c}36 \\
0\end{array}$ & $\begin{array}{c}36 \\
0\end{array}$ & $\begin{array}{l}3 \\
0\end{array}$ & 2 & $\begin{array}{c}110 \\
0\end{array}$ & $\begin{array}{l}\text { YES } \\
\text { NO }\end{array}$ & $\begin{array}{l}\text { NONE }^{5} \\
\text { ENRAF }\end{array}$ \\
\hline B-101 & ASMD LKR & IS/II & 113 & 0 & 6 & 6 & 0 & 113 & 0 & YES & $N O N E^{8}$ \\
\hline B-102 & SOUND & IS/II & 32 & 4 & 0 & 4 & 0 & 18 & 10 & YES & ENRAF \\
\hline B-103 & ASMD LKR & IS/II & 59 & 0 & 0 & 0 & 0 & 59 & 0 & NO & NONE \\
\hline B-104 & SOUND & $|S /| \mid$ & 371 & 1 & 46 & 47 & 40 & 301 & 69 & YES & ILL \\
\hline B-105 & ASMD LKR & IS/II & 306 & 0 & 23 & 23 & 0 & 40 & 266 & YES & ILL, MT \\
\hline B-106 & SOUND & IS/II & 117 & 1 & 6 & 7 & 0 & 116 & 0 & YES & $N^{\prime} E^{8}$ \\
\hline B-107 & ASMD LKR & IS/II & 165 & 1 & 12 & 13 & 7 & 164 & 0 & YES & NONE ${ }^{8}$ \\
\hline B-108 & SOUND & $|S /| \mid$ & 94 & 0 & 4 & 4 & 0 & 94 & 0 & NO & NONE \\
\hline B-109 & SOUND & $|S / I|$ & 127 & 0 & 8 & 8 & 0 & 127 & 0 & YES & $N O N E^{8}$ \\
\hline$B-110$ & ASMD LKR & $|\mathbf{S} /|$ & 246 & 1 & 22 & 23 & 17 & 245 & 0 & YES & ILL, MT \\
\hline B-111 & ASMD LKR & $|S /| \mid$ & 237 & 1 & 21 & 22 & 16 & 236 & 0 & YES & ILL, FIC \\
\hline B-112 & ASMD LKR & IS/II & 33 & 3 & 0 & 3 & 0 & 30 & 0 & YES & ENRAF \\
\hline B-201 & ASMD LKR & IS/II & 29 & 1 & 3 & 4 & 0 & 28 & 0 & NO & NONE \\
\hline B-202 & SOUND & $|S /| \mid$ & 27 & 0 & 3 & 3 & 0 & 27 & 0 & NO & NONE \\
\hline B-203 & ASMD LKR & $|\mathbf{S} /|$ & 51 & 1 & 5 & 6 & 0 & 50 & 0 & YES & $N^{\prime} N^{8}$ \\
\hline B-204 & ASMD LKR & $|S /| \mid$ & 50 & 1 & 5 & 6 & 0 & 49 & 0 & YES & NONE $^{8}$ \\
\hline BX-101 & ASMD LKR & $|\mathbf{I S} /|$ & 43 & 1 & 0 & 1 & 0 & 42 & 0 & NO & NONE \\
\hline BX-102 & ASMD LKR & $|S /| \mid$ & 96 & 0 & 4 & 4 & 0 & 96 & 0 & NO & NONE \\
\hline $8 X-103$ & SOUND & $\mid \mathrm{S} / \|$ & 68 & 6 & 0 & 6 & 0 & 62 & 0 & YES & ENRAF \\
\hline BX-104 & SOUND & IS/II & 99 & 3 & 30 & 33 & 27 & 96 & 0 & YES & ENRAF \\
\hline$B X-105$ & SOUND & $|S / I|$ & 51 & 5 & 6 & 11 & 4 & 43 & 3 & YES & ENRAF \\
\hline BX-106 & SOUND & $/ \mathrm{PI}$ & 38 & 0 & 0 & 0 & 0 & 38 & 0 & NO & NONE \\
\hline BX-107 & SOUND & IS/PI & 345 & 1 & 29 & 30 & 23 & 344 & 0 & YES & NONE $^{8}$ \\
\hline BX-108 & ASMD LKR & $|S /| \mid$ & 26 & 0 & 1 & 1 & 0 & 26 & 0 & NO & NONE \\
\hline BX-109 & SOUND & $|S / P|$ & 193 & 0 & 13 & 13 & 8 & 193 & 0 & YES & NONE $^{8}$ \\
\hline BX-110 & ASMD LKR & $I S / P \mid$ & 207 & 3 & 16 & 19 & 13 & 195 & 9 & YES & ENRAF \\
\hline$B X-111$ & ASMD LKR & $/ \mathrm{PI}$ & 162 & 1 & 1 & 3 & 1 & 52 & 109 & NO & NONE \\
\hline BX-112 & SOUND & IS/PI & 165 & 1 & 7 & 8 & 2 & 164 & 0 & YES & NONE $^{8}$ \\
\hline BY-101 & SOUND & $|\mathbf{S} / 1|$ & 387 & 0 & 5 & 5 & 0 & 109 & 278 & YES & ILL \\
\hline BY-102 & SOUND & IPI & 277 & 0 & 11 & 11 & 0 & 0 & 277 & YES & ILL \\
\hline BY-103 & ASMD LKR & $|P|$ & 414 & 0 & 38 & 38 & 32 & 5 & 409 & YES & ILL \\
\hline BY-104 & SOUND & $|S /| \mid$ & 406 & 0 & 18 & 18 & 0 & 40 & 366 & YES & ILL \\
\hline BY-105 & ASMD LKR & $\mid \mathbf{P I}$ & 503 & 0 & 228 & 228 & 216 & 44 & 459 & YES & ILL \\
\hline
\end{tabular}




\begin{tabular}{|c|c|c|c|c|c|c|c|c|c|c|c|}
\hline Tank & 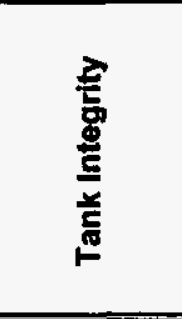 & 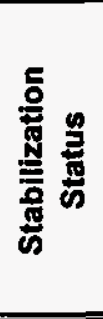 & 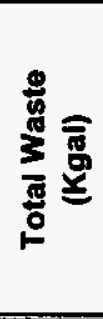 & 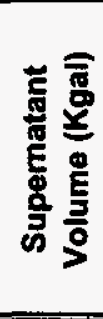 & 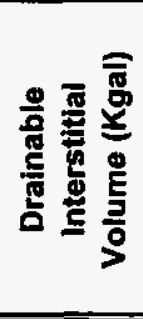 & 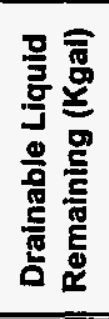 & 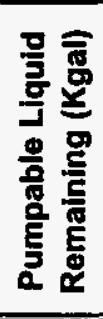 & 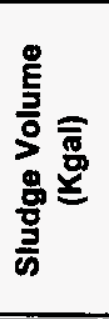 & 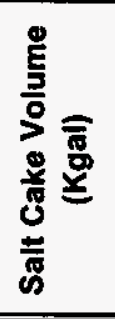 & 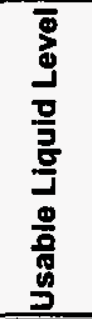 & 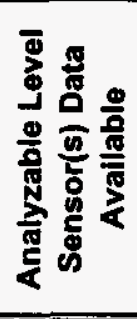 \\
\hline$B Y-106$ & ASMD LKR & $|\mathrm{P}|$ & 642 & 0 & 200 & 200 & 163 & 95 & 547 & YES & ILL \\
\hline BY-107 & ASMD LKR & IS/II & 266 & 0 & 25 & 25 & 0 & 60 & 206 & YES & ILL \\
\hline BY-108 & ASMD LKR & $|S /| \mid$ & 228 & 0 & 9 & 9 & 0 & 154 & 74 & YES & NONE 8 \\
\hline BY-109 & SOUND & $\mid \mathrm{PI}$ & 290 & 0 & 37 & 37 & 20 & 57 & 233 & YES & ILL \\
\hline$B Y-110$ & SOUND & $|S / I|$ & 398 & 0 & 9 & 9 & 0 & 103 & 295 & YES & ILL \\
\hline$B Y-111$ & SOUND & $|S / I|$ & 459 & 0 & 0 & 0 & 0 & 21 & 438 & NO & NONE \\
\hline BY-112 & SOUND & $|S /| \mid$ & 291 & 0 & 8 & 8 & 0 & 5 & 286 & YES & ILL \\
\hline C-101 & ASMD LKR & $|S /| \mid$ & 88 & 0 & 3 & 3 & 0 & 88 & 0 & NO & NONE \\
\hline C-102 & SOUND & IPI & 316 & 0 & 46.7 & 30 & 17 & 316 & 0 & YES & NONE ${ }^{8}$ \\
\hline C-103 & SOUND & IPI & 195 & 133 & 0 & 135 & 133 & 62 & 0 & YES & ENRAF \\
\hline C-104 & SOUND & IS/II & 295 & 0 & 0 & 11 & 5 & 295 & 0 & NO & NONE \\
\hline C-105 & SOUND & IPI & 134 & 2 & 0 & 32 & 9 & 132 & 0 & NO & NONE \\
\hline$C-106$ & SOUND & $\mathbb{P I}$ & 229 & 32 & 0 & 62 & 52 & 197 & 0 & YES & ENRAF \\
\hline C-107 & SOUND & IPI & 237 & 0 & 40.8 & 24 & 15 & 237 & 0 & YES & NONE ${ }^{8}$ \\
\hline$C-108$ & SOUND & $|S / I|$ & 66 & 0 & 0 & 0 & 0 & 66 & 0 & NO & NONE \\
\hline C-109 & SOUND & IS/I! & 66 & 4 & 0 & 4 & 0 & 62 & 0 & NO & NONE \\
\hline C-110 & ASMD LKR & $/ \mathrm{PI}$ & 178 & 1 & 28 & 29 & 15 & 177 & 0 & YES & NONE \\
\hline C-111 & ASMD LKR & IS/II & 57 & 0 & 0 & 0 & 0 & 57 & 0 & NO & NONE \\
\hline C-112 & SOUND & IS/PI & 104 & 0 & 0 & 32 & 26 & 104 & 0 & No & NONE \\
\hline C-201 & ASMD LKR & IS/II & 2 & 0 & 0 & 0 & 0 & 2 & 0 & NO & NONE \\
\hline $\mathrm{C}-2 \mathrm{O} 2$ & ASMD LKR & $|S /| \mid$ & 1 & 0 & 0 & 0 & 0 & 1 & 0 & NO & NONE \\
\hline C-203 & ASMD LKR & $|S /| \mid$ & 5 & 0 & 0 & 0 & 0 & 5 & 0 & NO & NONE \\
\hline C-204 & ASMD LKR & IS/II & 3 & 0 & 0 & 0 & 0 & 3 & 0 & NO & NONE \\
\hline S-101 & SOUND & IPI & 427 & 12 & 126 & 138 & 127 & 244 & 171 & YES & ENRAF \\
\hline S-102 & SOUND & IPI & 549 & 0 & 262 & 262 & 239 & 4 & 545 & YES & ILL \\
\hline S-103 & SOUND & $|P|$ & 248 & 17 & 101 & 118 & 97 & 10 & 221 & YES & ENRAF \\
\hline S-104 & ASMD LKR & IS/II & 294 & 1 & 28 & 29 & 23 & 293 & 0 & YES & ILL \\
\hline S-105 & SOUND & $|S / I|$ & 456 & 0 & 35 & 35 & 13 & 2 & 454 & YES & ILL \\
\hline S-106 & SOUND & $\mid \mathrm{PI}$ & 479 & 4 & 186 & 190 & 168 & 28 & 447 & YES & ENRAF \\
\hline S-107 & SOUND & IPI & 376 & 14 & 85 & 99 & 88 & 293 & 69 & YES & ENRAF \\
\hline S-108 & SOUND & $\mathbb{P I}$ & 450 & 0 & 4 & 4 & 0 & 4 & 446 & YES & ILL \\
\hline S-109 & SOUND & IPI & 568 & 0 & 141 & 141 & 119 & 13 & 555 & YES & ILL \\
\hline S-110 & SOUND & $\mid \mathrm{PI}$ & 390 & 0 & 30 & 30 & 23 & 131 & 259 & YES & ILL \\
\hline$S-111$ & SOUND & $|P|$ & 540 & 23 & 195 & 205 & 134 & 139 & 378 & YES & ENRAF \\
\hline S-112 & SOUND & $/ \mathrm{PI}$ & 523 & 0 & 110 & 110 & 107 & 5 & 517.7 & YES & ILL \\
\hline SX-101 & SOUND & IPI & 456 & 1 & 184 & 185 & 174 & 112 & 343 & YES & ILL. \\
\hline$s x-102$ & SOUND & $\mid \mathrm{PI}$ & 543 & 0 & 226 & 226 & 216 & 117 & 426 & YES & ILL \\
\hline$S X-103$ & SOUND & IPI & 652 & 1 & 281 & 282 & 272 & 115 & 536 & YES & ILL \\
\hline SX-104 & ASMD LKR & $/ \mathrm{PI}$ & 614 & 0 & 201 & 201 & 195 & 136 & 477.9 & YES & ILL \\
\hline SX-105 & SOUND & IPI & 683 & 0 & 309 & 309 & 299 & 73 & 610 & YES & ILL \\
\hline$S X-106$ & SOUND & IPI & 538 & 61 & 224 & 285 & 264 & 12 & 465 & YES & ENRAF \\
\hline$\$ x-107$ & ASMD LKR & $|S /|$ & 104 & 0 & 5 & 5 & 0 & 104 & 0 & YES & NONE ${ }^{8}$ \\
\hline$S X-108$ & ASMD LKR & IS/II & 87 & 0 & 5 & 5 & 0 & 87 & 0 & YES & NONE $^{8}$ \\
\hline
\end{tabular}




\begin{tabular}{|c|c|c|c|c|c|c|c|c|c|c|c|}
\hline Tank & 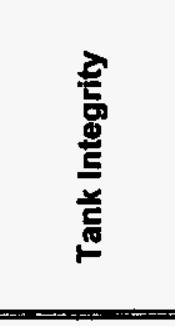 & 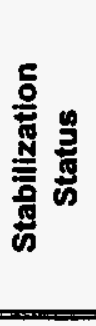 & 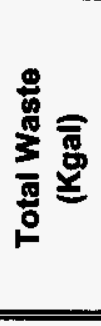 & 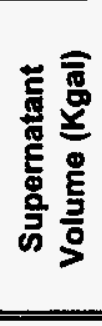 & 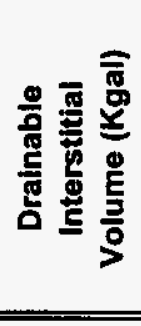 & 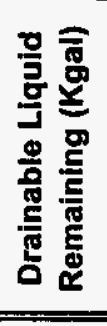 & 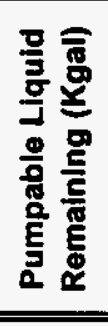 & 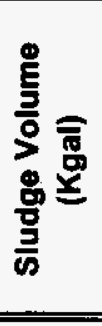 & 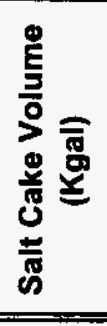 & 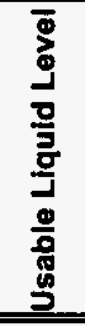 & 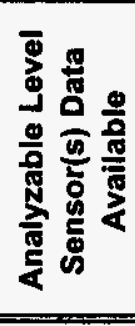 \\
\hline $\begin{array}{l}s x-109 \\
s x-110\end{array}$ & $\begin{array}{l}\text { ASMD LKR } \\
\text { ASMD LKR }\end{array}$ & $\begin{array}{l}|S /| \mid \\
|S /| \mid\end{array}$ & $\begin{array}{c}244 \\
62\end{array}$ & $\begin{array}{l}0 \\
0\end{array}$ & $\begin{array}{c}48 \\
0\end{array}$ & $\begin{array}{c}48 \\
0\end{array}$ & 25 & 0 & 244 & YES & NONE ${ }^{8}$ \\
\hline$s X-111$ & ASMD LKR & $|S /|$ & 125 & 0 & 7 & 7 & 0 & 125 & 0 & YES & NONE ${ }^{8}$ \\
\hline$S X-112$ & ASMD LKR & $|S /| \mid$ & 92 & 0 & 3 & 3 & 0 & 92 & 0 & NO & NONE \\
\hline$S X-113$ & ASMD LKR & IS/I & 26 & 0 & 0 & 0 & 0 & 26 & 0 & NO & NONE \\
\hline sX-114 & ASMD LKR & IS/II & 181 & 0 & 14 & 14 & 0 & 181 & 0 & YES & NONE ${ }^{8}$ \\
\hline$S X-115$ & ASMD LKR & IS/II & 12 & 0 & 0 & 0 & 0 & 12 & 0 & NO & NONE \\
\hline$T-101$ & ASMD LKR & $|S / P|$ & 102 & 1 & 16 & 17 & 0 & 101 & 0 & YES & NONE $E^{8}$ \\
\hline $\mathrm{T}-102$ & SOUND & IS/II & 32 & 13 & 0 & 13 & 13 & 19 & 0 & YES & ENRAF \\
\hline $\begin{array}{l}T-103 \\
T-104\end{array}$ & $\begin{array}{l}\text { ASMD LKR } \\
\text { SOUND }\end{array}$ & $\begin{array}{r}\text { IS/II } \\
\mid \mathrm{PI}\end{array}$ & $\begin{array}{c}27 \\
343\end{array}$ & $\begin{array}{l}4 \\
0\end{array}$ & $\begin{array}{c}0 \\
67\end{array}$ & $\begin{array}{c}4 \\
67\end{array}$ & $\begin{array}{c}0 \\
64\end{array}$ & $\begin{array}{c}23 \\
343\end{array}$ & $\begin{array}{l}0 \\
0\end{array}$ & $\begin{array}{l}\text { NO } \\
\text { YES }\end{array}$ & $\begin{array}{l}\text { NONE }^{6} \\
\text { ILL }\end{array}$ \\
\hline$T-105$ & SOUND & IS/II & 98 & 0 & 23 & 23 & 17 & 98 & 0 & YES & NONE $^{8}$ \\
\hline $\mathrm{T}-106$ & ASMD LKR & IS/II & 21 & 2 & 0 & 2 & 0 & 19 & 0 & NO & NONE \\
\hline $\mathrm{T}-107$ & ASMD LKR & $\mid \mathrm{PI}$ & 173 & 0 & 22 & 22 & 12 & 173 & 0 & YES & NONE $^{8}$ \\
\hline$T-108$ & ASMD LKR & IS/II & 44 & 0 & 0 & 0 & 0 & 44 & 0 & NO & NONE \\
\hline $\mathrm{T}-109$ & ASMD LKR & $|S /| \mid$ & 58 & 0 & 0 & 0 & 0 & 58 & 0 & NO & NONE \\
\hline$T-110$ & SOUND & IPI & 369 & 0 & 26 & 26 & 23 & 369 & 0 & YES & ILL \\
\hline$T-111$ & ASMD LKR & IPI & 446 & 0 & 34 & 34 & 29 & 446 & 0 & YES & ILL \\
\hline $\mathrm{T}-112$ & SOUND & IS/II & 67 & 7 & 0 & 7 & 7 & 60 & 0 & YES & ENRAF \\
\hline T-201 & SOUND & IS/II & 29 & 1 & 3 & 4 & 0 & 28 & 0 & NO & NONE \\
\hline T-202 & SOUND & IS/II & 21 & 0 & 2 & 2 & 0 & 21 & 0 & NO & NONE \\
\hline T-203 & SOUND & IS/II & 35 & 0 & 4 & 4 & 0 & 35 & 0 & NO & NONE \\
\hline$T-204$ & SOUND & IS/I & 38 & 0 & 4 & 4 & 0 & 38 & 0 & NO & NONE \\
\hline $\mathrm{TX}-101$ & SOUND & IS/II & 87 & 3 & 2 & 5 & 0 & 84 & 0 & YES & ENRAF \\
\hline$T X-102$ & SOUND & IS/II & 217 & 0 & 22 & 22 & 0 & 0 & 217 & YES & ILL \\
\hline$T X-103$ & SOUND & $|\mathbf{I S} /|$ & 157 & 0 & 15 & 15 & 0 & 157 & 0 & YES & NONE $^{8}$ \\
\hline TX-104 & SOUND & $|S / I|$ & 65 & 1 & 14 & 15 & 0 & 0 & 64 & YES & NONE ${ }^{8}$ \\
\hline$T X-105$ & ASMD LKR & IS/II & 609 & 0 & 20 & 20 & 0 & 0 & 609 & YES & NONE ${ }^{8}$ \\
\hline$T X-106$ & SOUND & $|S /|$ & 453 & 0 & 10 & 10 & 0 & 0 & 453 & YES & ILL \\
\hline TX-107 & ASMD LKR & IS/II & 36 & 1 & 1 & 2 & 0 & 0 & 35 & NO & NONE \\
\hline$T X-108$ & SOUND & IS/II & 134 & 0 & 0 & 0 & 0 & 0 & 134 & NO & NONE \\
\hline$T X-109$ & SOUND & IS/II & 384 & 0 & 10 & 10 & 0 & 0 & 384 & YES & ILL \\
\hline $\mathrm{TX}-110$ & ASMD LKR & $|S /|$ & 462 & 0 & 15 & 15 & 0 & 0 & 462 & YES & ILL \\
\hline$T X-111$ & SOUND & $|S /| \mid$ & 370 & 0 & 9 & 9 & 0 & 0 & 370 & YES & ILL \\
\hline$T X-112$ & SOUND & IS/I & 649 & 0 & 24 & 24 & 0 & 0 & 649 & YES & ILLL \\
\hline$T X-113$ & ASMD LKR & IS/II & 607 & 0 & 16 & 16 & 0 & 0 & 607 & YES & ILL \\
\hline TX-114 & ASMD LKR & IS/I & 535 & 0 & 15 & 15 & 0 & 0 & 535 & YES & ILL \\
\hline TX-115 & ASMD LKR & IS/I & 640 & 0 & 19 & 19 & 0 & 0 & 640 & YES & ILL \\
\hline$T X-116$ & ASMD LKR & $|S /|$ & 631 & 0 & 23 & 23 & 0 & 0 & 631 & YES & NONE $^{8}$ \\
\hline TX-117 & ASMD LKR & $|S /|$ & 626 & 0 & 8 & 8 & 0 & 0 & 626 & YES & ILL \\
\hline$T X-118$ & SOUND & IS/II & 347 & 0 & 27 & 27 & 0 & 0 & 347 & YES & ILL \\
\hline TY-101 & ASMD LKR & IS/I & 118 & 0 & 0 & 0 & 0 & 118 & 0 & NO & NONE \\
\hline TY-102 & SOUND & IS/II & 64 & 0 & 14 & 14 & 0 & 0 & 64 & YES & NONE ${ }^{8}$ \\
\hline
\end{tabular}




\begin{tabular}{|c|c|c|c|c|c|c|c|c|c|c|c|}
\hline Tank & 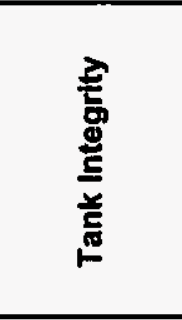 & 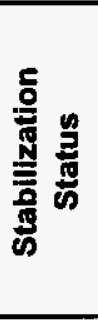 & 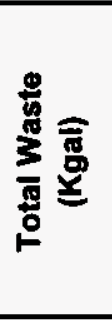 & 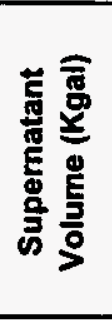 & 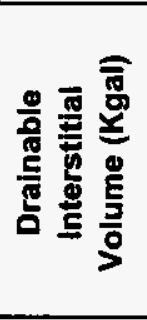 & 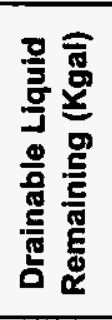 & 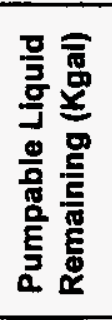 & 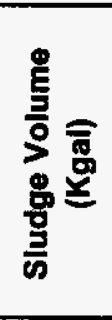 & 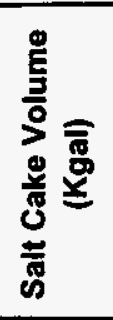 & 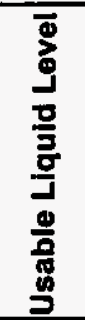 & 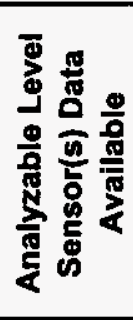 \\
\hline$T Y-103$ & ASMD LKR & IS/II & 162 & 0 & 5 & 5 & 0 & 162 & 0 & YES & ILL \\
\hline$T Y-104$ & ASMD LKR & $|S /| \mid$ & 46 & 3 & 12 & 15 & 0 & 43 & 0 & YES & ENRAF \\
\hline TY-105 & ASMD LKR & $|\mathbf{S} /| \mid$ & 231 & 0 & 0 & 0 & 0 & 231 & 0 & NO & NONE \\
\hline$T Y-106$ & ASMD LKR & $|S /| \mid$ & 17 & 0 & 0 & 0 & 0 & 17 & 0 & NO & NONE \\
\hline$U-101$ & ASMD LKR & IS/II & 25 & 3 & 0 & 3 & 0 & 22 & 0 & YES & MT \\
\hline$U-102$ & SOUND & $/ P I$ & 374 & 18 & 154 & 172 & 160 & 43 & 313 & YES & ILL \\
\hline$U-103$ & SOUND & $I P I$ & 468 & 13 & 207 & 220 & 205 & 32 & 423 & YES & ENRAF \\
\hline$U-104$ & ASMD LKR & $|\mathrm{S} /| \mid$ & 122 & 0 & 7 & 7 & 0 & 122 & 0 & YES & $N^{N O N E}{ }^{8}$ \\
\hline$U-105$ & SOUND & $\mid \mathrm{PI}$ & 418 & 37 & 170 & 207 & 192 & 32 & 349 & YES & ENRAF \\
\hline$U-106$ & SOUND & $\mid \mathrm{PI}$ & 226 & 15 & 87 & 102 & 85 & 26 & 185 & YES & ENRAF \\
\hline$U-107$ & SOUND & PI & 406 & 31 & 172 & 203 & 183 & 15 & 360 & YES & ENRAF \\
\hline U-108 & SOUND & IPI & 468 & 24 & 202 & 226 & 209 & 29 & 415 & YES & ILL \\
\hline U-109 & SOUND & IPI & 463 & 19 & 197 & 216 & 205 & 48 & 396 & YES & ENRAF \\
\hline$U-110$ & ASMD LKR & IS/PI & 186 & 0 & 15 & 15 & 9 & 186 & 0 & YES & NONE $^{8}$ \\
\hline$U-111$ & SOUND & IPI & 329 & 0 & 146 & 146 & 129 & 26 & 303 & YES & ILL \\
\hline $\mathrm{U}-112$ & ASMD LKR & IS/II & 49 & 4 & 0 & 4 & 0 & 45 & 0 & NO & NONE \\
\hline U-201 & SOUND & $|S /| \mid$ & 5 & 1 & 0 & 1 & 0 & 4 & 0 & NO & NONE \\
\hline U-202 & SOUND & $|\mathrm{S} /| \mid$ & 5 & 1 & 0 & 1 & 0 & 4 & 0 & NO & NONE \\
\hline U-203 & SOUND & $|S / I|$ & 3 & 1 & 0 & 1 & 0 & 2 & 0 & NO & NONE \\
\hline$U-204$ & SOUND & $\mid S / \|$ & 3 & 1 & 0 & 1 & 0 & 2 & 0 & NO & NONE \\
\hline
\end{tabular}

Notes:

1: Stabilization Status: "IS" = interim stabilized; "II" = interim isolated; "PI" = partially interim isolated.

2: Liquid volumes determined from photos.

3: Manual Tape data.

4: Monthly ENRAF data.

5: Monthly FIC data.

6: Discontinuous data

7: Only old data available ('81 - '89)

8: No Neutron ILL data 